\title{
THEORISATION OF STRUCTURAL BEHAVIOR WITH A VIEW TO DEFINING RESISTANCE AND ULTIMATE DEFORMABILITY +
}

\author{
R. Park*
}

\section{$\underline{A B S T R A C T}$}

This report reviews theoretical investigations which have been conducted to determine the behaviour of reinforced concrete, prestressed concrete and structural steel elements subjected to well defined repeated and reversed loading of high intensity. It commences with a brief summary of the stressstrain characteristics of the materials under such loading in the plastic range and then reports on theoretical methods for determining the moment-curvature and load-displacement characteristics of the members. Some consideration is also given to complete structures. Areas where future research is necessary are indicated.

\section{INTRODUCTION}

The use of digital computers has permitted rapid advances in the analyses of structures subjected to loading in the inelastic range. However the study of the factors on which such analyses are based, namely the load-deformation characteristics of structural members in the inelastic range, particularly at large deformations, has not kept up with these advances. This is well illustrated by the inaccurate elasto-plastic idealization for the load-deformation behaviour of elements which has generally been used to predict the response of structural steel and reinforced concrete frames to seismic ground motions.

This report reviews theoretical investigations which have been conducted to determine the load-deformation behaviour of reinforced concrete, prestressed concrete and structural steel elements subjected to well defined repeated and reversed loading. It commences with a brief sumary of the stressustrain characteristics of the materials under such loading and then reports on theoretical methods for determining the moment-curvature and loaddisplacement characteristics of structural members. Some consideration is also given to the behaviour of complete structures. Areas where future research is necessary are indicated.

2. STRESS-STRAIN CHARACTERISTICS OF CONCRETE AND STEEL Theory for structural behaviour must of

+ This paper is to be presented at a symposium of the International Association for Bridge and Structural Engineering entitled "Resistance and Ultimate Deformability of Structures acted on by well Defined Loads" to be held in Lisbon in September 1973.

* Professor of Civil Engineering, University of Canterbury, New Zealand. necessity be based on experimental data for the stress-strain characteristics of the materials. This report will not be concerned with the problem of ordinary fatigue in which the stress levels are genexally low enough for the stressustrain relationships to remain practically linear. Instead, the area of interest is that of low-cycle fatigue in which extensive non-linear behaviour occurs due to a few cycles of high intensity loading well into the yield range. Experimental data for the repeated and reversed loading behaviour of materials in this range, particularly at rapid rates of loading, is scarce. The behaviour of concrete and steel under such loading will be briefly reviewed to establish the stress-strain characteristics.

\subsection{Concrete}

A large number of experimental investigations have been conducted to determine the stress-strain curve for concrete in compression under a single load application to failure. Stress-strain curves proposed on the basis of such data for slow strain rates have been reviewed by Popovics(I) for unconfined concrete and Kent and Park(2) for concrete confined by rectangular steel hoops. For a single application of load af a fast strain rate Fatano and Tsutsumi (3), Ban and Mugurma (4) and others have shown that the modulus of elasticity and the strength increase with strain rate, as illustrated in Fig. 1. The strain at which maximum stress is reached appears to remain reasonably constant regardless of the strain rate.

The effect of repeated high intensity compressive loading of concrete is to produce a pronounced hysteresis effect in the stressstrain curve. Fig. 2 shows test data obtained by Sinha, Gerstle and Tulin (5) for slow strain rates. Their low-cycle fatigue tests indicated that the stress-strain curves of concrete under compressive load histories possess an envelope curve which may be considered unique and identical with the stress-strain curve obtained from a single load application. Repeated load tests by Karsan and Jirsa(6) at slow strain rates have also shown agreement with this conclusion. Both Sinha, et al, and Karsan and Jirsa, have proposed equations for the stress-strain loops for repeated compressive load developed using the observed responses of the specimens. Karsan and Jirsa also determined the number of cycles of repeated loading required to cause failure at various stress levels. For example, approximately 100 load applications to a load of 0.86 of the strength obtained from a single load application was required to cause failure. Shah and winter (7) in repeated compressive load tests at a slow strain rates 
have also found evidence of a shake-down limit for the strength. In applying between 5 and 20 loading cycles to concrete cylinders they found that repeated loading below 88 to $95 \%$ of the short-term ultimate strength did not alter the load carrying capacity of the concrete as determined by a single loading cycle, but that loads above this limit did damage the concrete. Results of tests on concrete prisms under repeated compressive loading at high strain rates have been reported by Polyakov, et al (8). The Exequency of loading was 100 to 300 cpm and the stress levels reached range from 0.6 to 0.95 of the static strength. The combined effect of rate of loading and 500 to 1000 cycles of load application was to reduce the strength as compared with a single application of static load by 10 to $18 \%$. However extrapolation of their results indicates that 50 cycles at $100 \mathrm{cpm}$ would not cause the strength to reduce to lower than the static strength. A further report by Polyakov, et al, (9) gives additional experimental evidence. A review of the classical results of fatigue tests conducted on concrete has been giver by Elores (10).

It is evident that the low-cycle fatigue characteristics of concrete have not yet been fully defined. Nevertheless the envelope law of Sinha, et al, and Rarsan and Jirsa, is an important statement and enables approximate stress-strain curves for repeated loading to be proposed based on hysteresis loops within the stress-strain curve for a single load application. However there is still a wide field of research open, particularly to determine complete stress-strain curves for repeated loading at rapid strain rates and for concrete confined by transverse steel hoops and spirals. Also, more research is required into the behaviour of concrete with complex stress conditions under repeated loading.

\subsection{Stee1}

The stress-strain curve for mild steel subjected to monotonic loading at a slow strain rate is well known. The stress-strain relationship can be represented by straight lines in the elastic and the plastic pre-strain hardening range, and by a curve in the strain hardening range, as shown in Fig. 3. The effect of a fast strain rate is to increase the yield stress of steel. For example, it has been reported (11) that for a strain rate of 0.01 in/in/sec the upper yeild stress may be raised by 1 to 328 , with the greater increase normally occurring for lower strength steel. The increase in the lower yield stress at this strain was up to 148 .

In the case of repeated high intensity loading of the same sign a small hysteresis effect occurs in the unloading and reloading stress-strain loop. The slope of this narrow hysteresis $100 \mathrm{p}$ is that of the initial elastic slope and when the stress regains the value at which unloading commenced the stress-strain curve continues as if unloading had not occurred. Hence the monotonic stress-strain curve forms an envelope for repeated loading of the same sign as illustrated in Fig. 3. The results of a repeated load test on high tensile steel prestressing wire is also shown in Fig. 4. Tests by Polyakov, et $a 1,(9)$ on steel reinforcement bars under repeated load in tension at 300 cycles per minute showed that the fracture load after 1000 cycles was only slightly less than the static strength obtained from one application, and hence that the fatigue and dynamic loading aspects were compensating each other.

Under cyclic (reversed) loading the stressstrain properties of steel become quite different from those associated with purely tensile or compressive stress. This is known as the Bauschinger effect and results in a lowering of the reversed yield stress. Once this phenomenon has been initiated by a yield excursion the linearity between stress and strain is lost over much of the loading range. This steel behaviour is strongly influenced by previous strain history: time and temperature also have an effect. Fig. 5 illustrates the Bauschinger effect. It should be noted that the unloading path follows the initial elastic slope. Examples of investigations of the behaviour of steel under cyclig loading are those by Singh, Gerstle and Tulin (12), Tanabashi, Yokoo, Nakamura, et al(13) and" Rent and Park (14, 15). Singh, et al, found that the history of previous loading had an effect on the curved part of the stress-strain curve but nevertheless from their experiments they arrived at a simple exponential curve representing the average of the family of reversed loading curves. Their tests were carried out on steel from only one batch. Tanabashi, et at, Kent and Park, and others, have found that an excellent representation of the loading parts of the stress-strain curve is given by a form of the Ramberg-osgood function (16) with empirical constants which depend mainly on the plastic strain amplitude. The shape of the hysteresis loop for loading in the plastic range shows a small change as the number of cycles of load increases. However the loop is remarkably stable if only a few cycles of loading are applied. Yao and Munse (17) have undertaken a comprehensive study of the low-cycle fatigue strength of metals and developed a theory for the failure of mild steel under low-cycle fatigue in terms of strain histories. Flores(10) has also given a summary of low-cycle fatigue: Tanabashi. et al (13) have quoted experimental results.

It is evident that, as with concrete, there is still need for much more research in this area. Comprehensive data on the stressstrain relationships of steel under low-cycle fatigue loading at slow and rapid strain rates has still to be obtained.

\section{THEORY FOR LOAD-DEFORMATION BEHAVIOUR OF REINFORCED CONCRETE}

The load-deflection characteristics of reinforced concrete members of usual proportions in the inelastic range are mainly dependent on the moment-curvature relationships of members. This is because where post-elastic behaviour is relied upon, such as in earthquake resistant design to dissipate energy, it is usual to ensure that shear and other types of brittle failure are prevented, and that ductile plastic hinges can occur by yielding of the flexural reinforcement.

Most of the existing evidence concerning the post-elastic behaviour of reinforced concrete members has been obtained from theoretical work or tests in which the loads have been applied monotonically until maximum load is reached. Only a few investigations have been conducted to determine the behaviour 
of reinforced concrete beam and column sections beyond the point of maximum load or under high intensity cyclic reversed loading. Examples of theoretical investigations into the behaviour of reinforced concrete members under cyclic loading are those of Aoyama(18), Sinha, Gerstle and Tulin(19), Agrawal, Tulin and Gerstle(20), Bertero and Bresler (2I), Brown and Jirsa(22) and Park, Kent and Sampson(23). The work of these authors will be discussed.

\subsection{Theoretical Determination of Moment-Curvature Relationships for Reinforced Concrete Sections}

Experimental studies of the response of reinforced concrete members have indicated that a significant loss of stiffness occurs during cyclic loading which results in an increase in the deformation at which the ultimate strength of the member is reached. Saillard (24) has reviewed much of the experimental work. It is only in recent times that the actual shape of the moment-curvature response has been predicted analytically. These theories have generally been based on an assumed linear strain profile down the depth of the section and idealized stress-strain curves for concrete and steel. The moment-curvature loop has usually been obtained by calculating the moment and curvature corresponding to a range of strains in the extreme fibre of the member. For a given strain in the extreme fibre the neutral axis depth is adjusted until the stresses in the concrete and steel, determined from the strain profile and the stress-strain curves for the materials taking the previous strain history into account, result in internal forces which balance the external forces acting on the section, and then the moment and curvature corresponding to that strain profile are calculated.

\section{Method of Aoyama (18)}

Aoyama developed a method of analysis to determine the moment-curvature relationships for a section subjected to constant axial load and reversal of bending. The initial load and the first reversal were considered. Deformations beyond first crushing of the concrete were not considered. The assumptions made for the analysis were a linear distribution of strain down the depth of the section and the idealized stress-strain relationships for steel and concrete shown in Fig. 6. As a result of a theoretical study on sections with equal top and bottom steel Aoyama found that the two most important variables effecting the momentcurvature loop were the amount of axial load and plastic strain in the previous load reversal. When the amount of axial load was small the moment-curvature diagram had a step in the first reversal curve due to closing of open cracks in the compression zone when the compression steel yields. At higher axial loads this step occurs at lower bending moments due to earlier yielding of the compression steel. Aoyama also conducted a series of static cyclic loading tests on simply supported beams with constant axial load and reversal of moment. A comparison of the theoretical and experimental moment-curvature curves for one beam in the region of pure bending is shown in Fig. 7 .

Aoyama's pioneering work successfuly explained the marked change in stiffness during cyclic loading tests. However the agreement with experimental results in the reversed loading runs was not good mainly because the assumed stress-strain curves for the concrete and steel were insufficiently accurate, and in particular the Bauschinger effect of the steel was neglected.

\section{$\frac{\text { Method of Sinha, Agrawal, Gerstle and }}{\text { Tulin }(19,20)}$}

Work at the University of Colorado has produced more complete theory for the momentcurvature response of beams to cyclic loading. A linear distribution of strains down the depth of the section was assumed. For singly reinforced beams with repeated loading of the same sign (19) the idealized stress-strain curves used were as shown in Fig. 8. For doubly reinforced beams with cyclic (reversed) loading (20) the idealized stress-strain curves assumed were as shown in Fig. 9. In particular it is to be noted that for the reversed loading case the stress-strain curve for the steel took into account the Bauschinger effect.

A series of static load tests were conducted on simply supported beams with symmetrical two point loading. The beam cross-section was 3 in. wide and 6 in. deep. The theoretical and experimental moment-curvature curves for a singly reinforced beam in the region of pure bending with repeated loading of the same sign are shown in Fig. 10. Fig. 11 shows compared the theoretical and experimental momentcurvature curves for a doubly reinforced beam in the region of pure bending with reversed loading. The agreement obtained between theory and experiment was good. It was considered that the response of doubly reinforced beams under reversed loading was predominantly influenced by the stress-strain characteristics of the steel and only slightly influenced by the concrete characteristics. The concrete characteristics could therefore be approximated by an idealized elasto-plastic curve whereas the complex non-linear stress-strain relationship for the steel needed to be used.

This work has given a clear lead to the accurate determination of the moment-curvature responses of reinforced concrete members.

Method of Bertero and Bresler (21)

Bertero and Breslex have discussed the possible effects of shear and bond forces on the deformation at the critical region of a beam adjacent to a beam-column joint.

Alternating shear forces may cause diagonal tension cracks which open and close in each direction. Also, at the stage in reversed loading before the compression steel yields, open cracks may exist in the compression zone. Therefore the shear force may have to be carried mainly by dowel action of the longitudinal steel which could lead to longitudinal splitting of the concrete along the bars. Hence high shear forces could cause a reduction in the stiffness of the members. Similarly, cyclic loading may cause a deterioration of the bond and lead to a reduction of stiffness due to slip of the bars. It was also pointed out that the effect of tensile stress carried by concrete between cracks needed to be included. In an attempt to produce a more accurate theory, the average curvature $\varphi$ at a particular point in the strain history was written as: 


$$
\phi=\left(\begin{array}{llll}
\alpha^{t} & \varepsilon_{s o}^{t}-\alpha^{b} & \varepsilon_{s o}^{b}
\end{array}\right) / a_{s}
$$

where $\varepsilon_{s o}^{t}$ and $\varepsilon_{s o}^{b}$ are the top and bottom steel strains at the cracked section, $d_{s}$ is the distance between. the top and bottom steel, and $\alpha^{t}$ and $\alpha$ axe the functions which characterize the bond effectiveness for a particular loading history. An expression was also written for crack widths in terms of bond effectiveness to determine the stage of opening and closing of cracks. The precise evaluation of the effect of these variables was not possible because of the lack of the basic experimental data required.

An analysis was carried out to determine the theoretical moment-curvature curve for the beam section adjacent to a beam-column joint tested by Hanson and Connor (25) under cyclic loading. The specimen $(V-A)$ had been subjected to cycilc loading without distress of the joint region. The beam has a cross section of 12 in. by $20 \mathrm{in}$. and contained 4 in 2 of steel in the top and 2 in $^{2}$ of steel in the bottom. The stress-strain curve for the stee $\frac{1}{2}$ assumed was that proposed by Agrawal, et al $(20)$ which included the Bauschinger effect. The concrete was assumed to have an envelope stress-strain curve based on a parabola and a linear falling branch, with Iinear unloading and parabolic loading loops unaffected by the previous strain history. The curvature was calculated using equation (1). The theoretical and experimental moment curvature curves are shown compared in Fig. 12. It was concluded that the deterioration in initial stiffness could not be predicted by consideration of bond deterioration in the beam alone but was also due to the additional effects of cracking and deformations due to shear and bond deterioration in the anchorage zone of the joint.

This work is an important account of the additional factors which can influence the determination of deformations of members from the moment-curvature relationships. The effect of shear and bond underlines the importance of detailing adequate transverse reinforcement for shear, confinement of the concrete and anchorage.

\section{Method of Brown and Jirsa}

Brown and Jirsa have computed theoretical moment-curvature responses for beam sections assuming a linear variation of strain with depth and idealized stress-strain curves for concrete including the effect of confining steel and for steel including the Bauschinger effect. These curves were used to determine the load-deflection responses of cantilever beams with cyclic loading and will be referred to later.

\section{Method of Park, Kent ánd Sampson}

Theoretical moment-curvature characteristics of reinforced concrete sections with cyclic loading were determined assuming a linear variation of strain with depth and the stress-strain curves for steel and concrete shown in Figs. 5 and 13. For the idealized stress-strain curve for the steel, the unloading path for stresses of both signs follows the initial elastic slope as does the reloading path, but after the first yield excursion the loading curve becomes nonlinear at low stresses due to the Bauschinger effect. The loading parts of the stress-strain curve was represented by the following form of the Ramberg-osgood relationship determined by kent and Park $(14,15)$.

$$
\varepsilon_{s}=\frac{f_{s}}{E_{s}}\left(1+\left|\frac{f_{s}}{f_{c h}}\right|^{r-1}\right)
$$

$$
\text { where } \begin{aligned}
f_{c h} & =f_{Y}\left\{\frac{0.744}{\log _{e}\left(1+1000 \varepsilon_{i p}\right)}-\frac{0.071}{\left(1-\varepsilon^{\left.1000 \varepsilon_{i p}\right)}\right.}\right. \\
& +0.241\}
\end{aligned}
$$

$$
\begin{aligned}
& \text { 5, For odd numbered loading runs }(n=1,3, \\
& r=\frac{4.49}{\log _{e}(1+n)}-\frac{6.03}{e^{n}-1}+0.297 \\
& \text { For even numbered loading runs ( } n=2,4 \text {, } \\
& \quad \ldots)=\frac{2.20}{\log _{e}(1+n)}-\frac{0.469}{e^{n}-1}+3.04
\end{aligned}
$$

and $\varepsilon_{\mathbf{s}}=$ steel strain, $f_{\mathbf{S}}=$ steel stress, $\mathrm{E}_{\mathbf{S}}=$ modulus of elasticity of steel, $\varepsilon_{i p}=$ plastic strain in steel produced in previotos loading run, and $\mathrm{n}=$ loading run number (first yield occurs at $n=0, n=1$ is the first post-yield stress reversal, $n=2$ is the second postyield stress reversal, etc.).

The envelope curve $A B C D$ for the stressstrain curve of the concrete in the compressive stress range shown in Fig. 13 was represented by the relationship determined by Kent and Park (2) for concrete confined by rectangular hoops under monotonic loading:

Region $\mathrm{AB}: \varepsilon_{\mathrm{c}}<0.002$

$$
f_{c}=f_{c}^{\prime}\left\{\frac{2 \varepsilon_{c}}{0.002}-\left(\frac{\varepsilon_{c}}{0.002}\right)^{2}\right\}
$$

where $f_{C}=$ concrete stress, $f_{\dot{C}}^{\prime}=$ concrete cylinder strength and $\varepsilon_{c}=$ concrete strain.

$$
\begin{gathered}
\text { Region BC: } 0.002<\varepsilon_{C}<\varepsilon_{20 \mathrm{C}} \\
f_{C}=f_{C}^{\prime}\left\{1-\mathrm{z}\left(\varepsilon_{\mathrm{C}}-0.002\right)\right\}
\end{gathered}
$$

where p" = ratio of volume of hoops to volume of concrete core, $b "=$ width of confined core, $s=$ hoop spacing and $f_{c}^{\prime}$ is in psi.

$$
\text { Region CD: } \varepsilon_{20 \mathrm{C}}<\varepsilon_{\mathrm{C}}
$$

$$
f_{c}=0.2 f_{c}^{\prime}
$$

where $\varepsilon_{20 c}=$ strain at 0.2 of maximum stress on falling branch of the stress-strain curve.

A linear stress-strain curve for concrete in 
tension is assumed with the same slope as the curve for compression at zero stress. The tensile strength (modulus of rupture) will be taken as that proposed by Warwaruk $(26)$ :

$$
f_{t}^{\prime}=\frac{1000 f_{c}^{\prime}}{4000+f_{c}^{\prime}} \text { psi }
$$

where $f_{C}^{\prime}$ is in psi. In the idealized repeated load behaviour illustrated in Fig. 13 the average slope of the loop from $E$ to $G$ is $E_{C}$. Also.it was assumed that if the concrete has not cracked it is capable of carrying tensile stress from $G$ to $k$, but if the concrete has previously cracked or cracks form during this loading stage the tensile strains increase without any tensile stress developing. On reloading the strain.must regain the value at $G$ before compressive stress can be sustained again.

The stress-strain curve for the cover concrete (outside the hoops of the member) in compression was assumed to follow the curve for the confined core at strains less than 0.004 . The cover concrete at strains greater than 0.004 was considered to have spalled and to have zero strength. This was considered necessary because the transverse steel leads to a plane of weakness between the core and the cover concrete and the cover concrete will become ineffective after several reversals of high intensity loading.

To compute the bending moment and curvature for cyclically loaded sections with or without axial compression the approach was to divide the concrete sections into a number of discrete elements. Each element has the width of the section at that level. If there are $n$ elements numbered from the top each will have depth $t / n$, where $t$ is the overall depth of the section. Fig. 14 shows the arrangement for a T section.

The top and bottom steel reside in elements $n d^{\prime} / t$ and $n d / t$ respectively. If the strain in the top fibre is $\varepsilon_{\mathrm{cm}}$ and the neutral axis depth is $k d$ then the average strain in element $i$ is given as

$$
\varepsilon_{i}=\varepsilon_{\mathrm{cm}} \frac{\mathrm{n} \frac{\mathrm{kd}}{\mathrm{t}}-i+0.5}{\mathrm{n} \frac{\mathrm{kd}}{\mathrm{t}}}
$$

The stress in the concrete and the steel in each element is found from the assumed stress-strain curves and is taken as that corresponding to the average strain in the element. An iterative technique is used to calculate points on the moment-curvature curves. The strain $\varepsilon$ in the top concrete fibre is adjusted by a fixed amount. For each value of $\varepsilon$, the neutral axis depth $k d$ is estimated and stresses in the elements computed for this strain profile. The forces acting on the elements are then calculated, and the equilibrium of the forces is checked. The neutral axis depth is adjusted until equilibrium of forces is achieved, and then the bending moment and curvature are calculated for the particular value of $\varepsilon_{\mathrm{cm}}$ and external axial load.

The discrete element technique has the advantage of coping with the unusual stress distributions which result from cyclic loading, and it is a simple matter to alter the element force for area reductions due to spalling and to record which elements have cracked. The technique has the disadvantage of being relatively slow in that it is necessary to store for each element the parameters that record the progress along the stress-strain path in order to calculate the stress corresponding to a given strain.

The theoretical approach was checked against experimental results(23) obtained from cyclically loaded doubly reinforced beams with a rectangular cross-section of width 4.94 in. and depth 8 in. The beams were simply supported over a $6 \mathrm{ft}$. span and were loaded statically at midspan through a column stub. Strains were measured on the top and bottom steel reinforcement and the experimental curvature was calculated from the steel strains. Fig. 15 shows a beam after testing. Figs. 16 and 17 show comparison of experimental and theoretical moment-curvature curves for two of the beams. Beam 24 contained equal top and bottom steel $\left(p=p^{\prime}=\right.$ 1.118 ) and beam 27 contained unequal top and bottom steel $\left(p=3.548, p^{\prime}=1.14 \%\right)$, where $\mathrm{p}=$ area of bottom steel $/ \mathrm{bd}, \mathrm{p}^{\prime}=$ area of top steel $/ b d, b=$ width of beam and $d=$ depth of bottom steel. Both beams contained $\frac{1}{4} "$ diameter closed stirrups at 2 in. centres $\left(p^{\prime \prime}=2.30 \%\right)$. All reinforcement was of mild steel. Lines rather than points indicate experimental curvature reflecting the creep at each increment. The theoretical curves were calculated between the experimental curvature points at which load reversal took place. The parts of the theoretical curves where moment is carried by a steel couple alone are indicated on the curves.

To assess the accuracy of the theoretical approach for column sections the experimental results obtained by Aoyama (18) for a member subjected to axial load and cyclically varying bending moment were checked against the theory. Aoyama's specimen A-2 was used and the comparison is shown in Fig. 18.

In Aoyama's paper the experimental momentcurvature points for increments 20 to 32 (the second load reversal) were drawn transferred to the symmetric position with respect to the origin in order to make a direct comparison with the points from the first load reversal (see Fig. 7). In Fig. 18 those experimental points (20 to 32 ) have been plotted transferred back to their actual position.

The agreement between the experimental and theoretical results found was good. Over a large proportion of the theoretical curves for beams the moment is carried by a steel couple alone. This behaviour has been noted by previous investigators and is due to yielding of the steel in tension causing cracks in the tension zone which, because of plastic elongation of the steel, do not close when the direction of moment is reversed. Open cracks will exist in the compression zone until the compression steel yields and enables the cracks to close. Only then will the concrete carry some of the compressive force. In particular for beams with different reinforcement top and bottom (Fig. 17), once the large area of steel has yieloded in tension, the concrete on that side of the member may not carry compression again because the tensile force in the small area of steel will be insufficient to cause the large area of steel in compression to 
yield. However when the direction of moment is reversed the small area of steel in compression will yield at a low moment. The beam of Fig. 16 had equal top and bottom steel, and after the first yield excursion the load is carried very largely by the steel couple. Therefore the shape of the moment-curvature loop is very much governed by the shape of the stress-strain loop for the steel. For column sections the effect of cracking may also be quite marked. In Fig. Is the regions of the theoretical curve where a steel couple alone is operating have not been indicated, but it is evident that in the early part of the moment-curvature curves after the first yield excursion the moment is carried only by the steel. For column sections the presence of axial compression as well as bending will mean that even for sections with equal steel in each face the steel in compression will yield at a low moment and close the crack.

The increase in the flexural stiffness due to closing of the cracks in the compression zone is more sudden in the theoretical curves than in the tests, as is shown in Fig. 17. This is probably because in practice some compression can be carried across cracks before they close. Particles of concrete which flake off during cracking and small relative shear displacements along the cracks cause compression to be transferred across the cracks gradually as high spots come into contact rather than suddenly as is implied in the theory.

Both the theoretical and experimental moment-curvature loops are far removed from the normally assumed parallelogram of classical elasto-plastic behaviour. For beams a better idealization for the actual shape of the loops would be the Ramberg-Osgood type response or the degrading stiffness response suggested by Clough (27) shown in Fig. 19. For beams with significantly different top and bottom steel areas, and for columns, the pinching in effect shown by the experimental and theoretical curves is more marked and a loop with a smaller area than the above idealizations would appear to be necessary.

\subsection{Theoretical Determination of Load-Deflection Relationships for Reinforced Concrete Members and structures}

If the curvature distribution along a member is known then, theoretically, the rotation between any two points $A$ and $B$ is given by

$$
\theta_{A B}=\int_{A}^{B} \varphi d s
$$

where $\phi$ is the curvature, and ds. is an element of length of the member. Also, the transverse deflection of point A from the tangent to the axis of the member at point $B$ is given by

$$
\Delta_{A B}=\int_{A}^{B} x \cdot \varphi d s
$$

where $\mathrm{x}$ is the distance of the element ds from A.

The above moment-area relationships may be used to determine the load-deflection characteristics of members. However they ignore the effect of shear cracks and deformations and of bond slip.

Shear deformations are difficult to take into account but the effect of diagonal tension cracking can be approximately included. Diagonal tension cracks tend to spread the zone of steel yielding further along the member than the bending moment diagram implies. Hence, in general, theoretical plastic deformations calculated from the bending moment diagram and the moment-curvature relationships will underestimate the actual rotations. Some investigators, for example sawyer $(28)$, have recommended the use of a horizontally displaced bending moment diagram when calculating rotations from curvature because of this effect. The effect of bond slip on the deformations can be included if the amount of slip is known.

\section{Method of Brown and Jirsa (22)}

Brown and Jirsa have calculated theoretical load-deflection curves for $5 \mathrm{ft}$. long cantilever beams with an 18 in. deep by 10 in. wide crosssection and compared them with test results for cyclically applied end loading. Fig. 20 shows the assumed curvature distribution and Fig. 21 the comparison for a beam. The theoretical end deflection was expressed as

$$
\Delta_{\mathrm{E}}=\left(\theta_{\mathrm{FE}}+\phi_{\mathrm{m}} \gamma\right) \mathrm{L}
$$

where $\theta_{\mathrm{FE}}=\Delta_{\mathrm{FE}} / \mathrm{d}_{\mathrm{S}}, \quad \Delta_{\mathrm{FE}}=$ slip of bars in fixed end, $\mathrm{d}_{\mathrm{S}}=$ distance between centroids of tension and compression steel, $\phi_{\mathrm{m}}=$ curvature at peak moment, $\gamma=$ yielded length of beam during previous half cycle and $L=$ length of beam. The contribution from the elastic portion of the beam was neglected. Measured values for $\Delta_{E}$ and $\gamma$ were used in equation (15). Fig. 21 indicates agreement between the theoretical and experimental results is reasonable. It is evident that the theory used is dependent on empirical values for $\Delta_{\mathrm{FE}}$ and $\gamma$.

Brown and Jirsa concluded from their tests that the effect of shear can be critical. Failure of all specimens was initiated by shear. apparently by large shear deformations along nearly vertical planes which were not crossed by stirrups. Also the deformation of steel in the anchorage zone (within the fixed end) contributed significantly to the total deformation.

$$
\text { Method of Park, Kent and Sampson (23) }
$$

Theoretical moment-curvature curves were used to determine the theoretical central. deflection of the cyclically loaded simply supported test beams described previously. The member was divided up into a number of longitudinal elements of short length and the moment at the centre of each element was assumed to be constant over the length of the element. Changes of deflection were obtained by adjusting the concrete strain $\varepsilon \mathrm{cm}$ at the extreme fibre of the centre-most element of the beam. The bending moment and curvature corresponding to that value of $\varepsilon_{\mathrm{cm}}$ was determined. The load producing this bending moment and the bending moments in the remaining elements was then established, and the $\varepsilon \mathrm{cm}$ value for each of the remaining elements was adjusted until the computed and the required bending moments coincided. Then the curvatures corresponding to the bending moments for all 
sections were calculated and the deflections computed from the curvatures. The theoretical load-central deflection curves so calculated for Beam 24 are shown in Fig. 22. In the theoretical analysis each half span of the beam (each side of the column stub) was divided into 9 longitudinal elements of equal length and the section of each element into 10 discrete horizontal elements. Ideally many more longitudinal elements should have been taken but, because so many iteration processes are involved, considerable computer time would have been necessary. The experimental points for the beam are also shown in Fig. 22. Generally the shapes of the theoretical and experimental loops are similar. In view of the considerable computer time required to produce the theoretical load-deflection plots some simplification is desirable. Fig. 23 shows the theoretical loaddeflection curves calculated using Clough's "degrading stiffness" moment-curvature assumption (27) of Fig. 19b. The analysis was performed. with both 10 and 100 longitudinal elements in each half span. The agreement between theory and experiment given by this idealization as shown in Fig. 23 is good. Note however, that clough's idealization does not simulate the pinching in effect which occurs in beams when the top and bottom steel areas are significantly different, and in columns, and hence should be used with caution in those cases.

The theoretical deflections shown in Fig. 22 and 23 have been calculated ignoring the stiffening effects of concrete tension between cracks. This evidently has not led to as much error as would be expected. In members under cyclic loading this stiffening effect of the concrete between cracks may not be very important. It is probable that a gradual break down of bond between concrete and steel occurs in members under high intensity cyclic loading which, in turn, reduces the influence of the concrete. Also, for these simply supported beams, slip of the bars in the anchorage zones at the ends of the member would have been negligible and was not taken into account. The theoretical calculations also ignored the effect of siear and the curvatures were determined from the actual moment diagram rather than the displaced diagram. Fig. 15 indicates that very little diagonal tension cracking occurred in the beams and the use of the actual moment diagram apparently was satisfactory in spite of the rather high nominal shear stress of 150 to 350 psi which existed at the plastic hinge sections at maximum load.

A point of interest is that the shape of the load-deflection curves for simple members under cyclic loading is very similar to the shape of the moment-curvature loops for the sections. This shows that reasonable idealizations for the load-deflection behaviour could be made.

\subsection{Complete Structures}

Massonnet and Save (29) have summarized some theoretical investigations of "shakedown" which show theoretically using idealized momentcurvature relationships that structures subjected to repeated loading can fail by progressive plastic deformation at loads which may be significantly less than the failure load from monotonic analysis. However experimentally obtained failure loads have normally exceeded such predictions. For example, Gerstle and Tulin $(30)$ in tests on reinforced concrete continuous beams under repeated loading found that incremental collapse would not occur at less than the monotonic load if strain hardening occurred.

To follow through in detail the theoretical load-deflection characteristics of a framed structure subjected to cyclic loading (typically, reversed lateral loading due to wind or earthquakes) using only the momentcurvature characteristics of the members. would appear to be an oversimplification. Additional deformations of framed structures can arise from shear deformations of the members, deterioration of anchorage of reinforcement bars (particularly at beam-column joints), and inelastic deformations in beam-column joint regions due to alternating diagonal tension cracks and yielding of shear reinforcement. For example, in the cyclic load tests conducted by Hanson and Connor (25) and Megget and Park (31) on beam-column assemblages it was found that joint distortion contributed significantly to the deformation of some specimens, and yielding of the beam steel penetrated well into the column. In fact it may be difficult to prevent shear and anchorage failures in exterior joints using standard reinforcement details. Also in the case of beam steel passing through interior columns there may be $a$ bond problem when there is reversal of moment through the joint. For example "compression steel" may actually be in tension if the bond in the joint deteriorates. This points to the need for good detailing of joints and other regions with high shear and anchorage forces. Empirical expressions for joint stiffness and shear deformation have been given by Umemura and Aoyama (32). More research is necessary to determine the order of these additional effects in typical structures.

\section{THEORY FOR LOAD-DEFORMATION BEHAVIOUR OF PRESTRESSED CONCRETE}

Experimental studies by Inomata

Spencer (34) and others have demonstrated the load-deformation characteristics of prestressed concrete members under cyclic loading. However there has been few attempts to determine such characteristics theoretically. Two existing methods will be reviewed below. It is evident that the moment-curvature relationships can be used to determine the load-deflection characteristics in the same way as for reinforced concrete.

Method of Parangama and Edwards

Paranagama and Edwards have developed a theoretical analysis to predict the momentcurvature relationships of prestressed concrete members under repeated loading of the same sign. The concrete and steel were assumed to have the stress-strain curves shown in Fig. 24. The monotonic moment-curvature curve was assumed to be the envelope of the repeated loading curves. Unloading and reloading curves were obtained assuming in addition that the change of concrete strains has a linear distribution down the section but that the change in steel strain corresponding to a change in curvature $\phi_{c}$ is given by.

$$
\varepsilon_{s c}=F\left(\varphi_{C} d-z\right)
$$

where $F$ is a strain compatability factor, d is the effective depth of the steel, and $z$ is the change in strain in the extreme concrete 
fibre. Strain compatability and equilibrium were used to calculate the theoretical curves.

Tests were conducted on simply supported beams over a 6 ft. span. Fig. 25 shows the measured moment-curvature curves for a beam with an 8 in. by 4 in. cross-section. Fig. 26 shows a theoretical moment-curvature diagram for a beam. The beams were pretensioned. It was possible to make the theoretical and experimental curves coincide by varying the value of the compatability factor $F$. The value of $F$ required to achieve this is shown in Fig. 26 . The value for $F$ so found had a high value initially when the beam first cracked and finally tended to a value close to unity. The theoretical stiffness found in the cracked. unloading and reloading phase did not agree with the experimental values obtained. However values for $F$ could be determined which would make the theoretical unloading curves have the same stiffness.

It is evident that better idealizations for the stress-strain curves than assumed by Paranagama and Edwards are necessary to obtain more accurate theoretical curves. The use of varying strain compatability factors should be unnecessary.

\section{Method of Blakeley and Park $(36,37)$}

Blakeley and Park have developed a theoretical method for determining the momentcurvature relationships of prestressed concrete under cyclic (reversed) loading. The method assumes a linear distribution of strain down the depth of the section $(F=1)$ and the idealized stress strain curves shown in Fig. 27.

The idealized curve for steel (Fig. 27a) was obtained from test results (for example, Fig. 4). The envelope curve was of the "Iinearhyperbolic-linear" type, fitted to the test results. The test results showed a hysteresis effect on unloading and reloading, particularly at high strains, and the slope of the unloading path reduced with increasing maximum strain. For the idealized hysteresis loops within the envelope, if $\varepsilon_{\mathrm{sm}}$ is the current maximum steel strain, the loop width $\mathrm{L}_{\mathrm{w}}$ was taken as zero if $\varepsilon_{\text {sm }}<0.009$ or $0.045 \varepsilon_{\text {sm }}$ if $\varepsilon_{\text {sm }}>0.009$; the modulus of elasticity factor was taken as 1.0 if $\varepsilon_{\mathrm{gm}}<0.012$ or $1.092-7.7 \varepsilon_{\mathrm{sm}}$ if $\varepsilon_{\mathrm{sm}}$ 0.012 .

The envelope stress-strain curve for the concrete (Fig. 27b) was that proposed by rent and Park (2) given by equations (6) to (11). For the idealized hysteresis loops within the envelope a degrađation of stiffness was assumed at strains greater than that corresponding to maximum stress as has been observed (see for example, Fig. 2). The value of $F$ which represents this degrading stiffness was taken as

$$
F_{C}=0.8-0.7\left(\varepsilon_{C m}-\varepsilon_{0}\right) /\left(\varepsilon_{20 c}-\varepsilon_{0}\right)
$$

where the notation is as shown in Fig. $27 \mathrm{~b}$. The cover concrete (outside the confining steel) was assumed to have the same stress-strain curve as the core up to a strain of 0.004 and to spall at higher strains.

The moment curvature relationships were determined asing the requirements of strain compatability and equilibrium and by dividing the sections up into discrete elements. This approach was similar to that used by Park, et al (23) for reinforced concrete except that the initial strains at the section due to prestress were taken into account. The theoretical moment-curvature curves for the plastic hinge sections of a 16 in. $x 7.63$ in. pretensioned column of a beam-column specimen (Unit 3) tested by Blakeley and Park (38) are shown compared with the experimental curves in Fig. 28. Good agreement was obtained with this and other comparisons and it was found that the envelope of the cyclic loading curves coincided almost exactly with the monotonic curve. It was noted that use of a strain compatability factor $F$ was unnecessary; this is contrary to the findings of Paranagama and Edwards (35). The inclusion of the hysteresis in the idealized stress-strain curve for the steel was necessary for good agreement.

On the basis of the test results, the idealized moment-curvature curves shown in Fig. 29 were proposed which include possible stiffness degradation after crushing of the concrete has occurred. Three stages of behaviour were idealized: stages 1,2 and 3 represent respectively behaviour before crushing, behaviour after crushing in one direction has occurred, and behaviour after crushing in both directions has occurred. Spencer (34) has also proposed an idealized loop for curvatures before crushing.

A feature of the moment-curvature behaviour illustrated in Figs. 28 and 29 is that prior to crushing of the concrete the elastic recovery of the section is high and the narrow hysteresis loops show little energy dissipation. However, at larger deformations when crushing of the concrete has commenced the energy dissipation is much greater although the recovery is still large.

\section{THEORY FOR LOAD-DEFORMATION BEHAVIOUR OF STRUCTURAL STEEL}

The load-deformation characteristics of structural steel members are mainly dependent on the moment-curvature relationships of the sections since most of the deformation arises from strains associated with flexure. However there have been very few theoretical studies conducted on the moment-curvature relationships of such members under cyclic (reversed) loading. More reliance has been placed on the use of test results to obtain moment-curvature relationships by direct measurement rather than by analytical methods from the stress-strain curves. This has been partly due to the lack of detailed experimental evidence of the stressstrain characteristics for steel subjected to cyclic loading. Also the calculation of the moment-curvature relationships is complicated by the presence of residual stresses in the steel, and there is a lack of information on the fatigue notch-sensitivity at welds and the effect of torsional and flange buckling on the fatigue life of the steel. Nevertheless theory can be derived on the basis of simplifying assumptions.

5.1 Theoretical Determination of Moment-Curvature Relationships for Structural steel sections

Method of Kaldjian (39)

Kaldjian has determined the theoretical 
moment-curvature curve for symmetrical sections for monotonic loading assuming a linear distribution of strain down the section depth and a stress-strain curve of the Ramberg-osgood type applicable in tension and compression. The stress-strain relation was written as

$$
\frac{\varepsilon}{\varepsilon_{y}}=\frac{\sigma}{\sigma_{y}} \quad\left(1+\left|\frac{\sigma}{\sigma_{y}}\right|^{r-1}\right)
$$

where $\varepsilon=$ the strain, $\varepsilon_{y}=$ the characteristic strain, $\sigma=$ the stress, $\sigma_{y}=$ characteristic stress, and $r=$ an exponent. The quantities $\varepsilon_{y}, \sigma_{y}$ and $r$ may be determined from test results. The stress-strain relation is shown in Fig. 30. Fig. 31 shows a rectangular section with moment applied resulting in stress $\sigma_{m}$ in the extreme fibres. The curvature is given by $\varepsilon_{\mathrm{m}} / \mathrm{c}$ and the moment of resistance of the section was found by integrating the stresses over the section. Kaldjian suggested that a wide-flange section could be closely approximated by the difference between two rectangles as shown in $\mathrm{Fig} .32$. The moment $\mathrm{M}_{\mathrm{WF}}$ for a wide-flange section was written as

$$
\mathrm{M}_{\mathrm{WF}}=\mathrm{M}_{\mathrm{A}}-\mathrm{M}_{\mathrm{B}}
$$

where the subscripts $A$ and $B$ refer respectively to the rectangles $A$ and $B$ in Fig. 32. Kaldjian determined the theoretical moment-curvature curves for typical wide-flange sections using the above approximation and found that they showed excellent agreement with the shape of moment-curvature curves given by the relationship

$$
\varphi_{\varphi_{Y}}=\frac{M}{\bar{M}_{Y}}\left(1+\left|\frac{M}{M_{Y}}\right|^{R-1}\right)
$$

where the parameters $\mathrm{M}_{\mathrm{y}}=$ characteristic moment, $\varphi_{\mathrm{y}}=$ characteristic curvature and $\mathrm{R}=$ an exponent are chosen to give the best fit by the least squares method. When the stressstrain parameters $\left(\varepsilon_{y}, \sigma_{y}\right.$ and $\left.r\right)$ were known the parameters in equation (20) were given with very good accuracy by $M_{y}=z_{x} \sigma_{y}, R=r$, and $\varphi_{y}=2 \varepsilon_{y} /\left(y_{p}+y_{E}\right)$ where $z_{x}=$ plastic section modulus, and $\mathrm{yp}_{\mathrm{p}}$ and $\mathrm{y}_{\mathrm{E}}=$ distance from neutral axis to the plastic and elastic centres of force (see Fig. 32).

\section{Method of Tanabashi, et al (13)}

Tanabashi, et al, have determined a theoretical solution to the steady state behaviour of cantilevers under cyclic loading. The wideflange section is replaced by an equivalent sandwich section which consists of two flanges carrying normal stress only and a shear resistant core which does not carry normal stress. Ranberg-osgood type equations were used for the stress-strain relationships.

\section{Alternative Methods}

- Although Kaldjian's approach does not take residual stresses into account it nevertheless could be used to obtain the skeleton curve of moment-curvature relationships. The branch curves for cyclic loading could then be defined from the skeleton curve using the Ramberg-Osgood relations as has been suggested by Jennings (40). For example, if $\mathrm{M}_{0}, \varphi$ are the coordinates of the point of origin of the branch curve (see Fig. 33) the equation for the branch curve becomes

$$
\frac{\varphi-\varphi_{0}}{2 \varphi_{Y}}=\frac{M-M_{O}}{2 M_{Y}}\left\{1+\left|\frac{M-M_{O}}{2 M_{Y}}\right|^{R-1}\right\}
$$

where $\mathrm{M}_{\mathrm{y}}, \varphi_{\mathrm{y}}$ and $\mathrm{R}$ are the parameters in the skeleton curve. This extension of Kaldjian's work requires experimental verification.

The work of Tanabashi, et al, (13) indicates that the above formulation may be over-simplified. However it should be noted that many tests have shown that severely strained steel beams under cyclic loading adjust themselves rapidly to steady state conditions. For example, Popov (41) has commented that a nearly stable hysteresis loop was formed as early as during the second half of the first cycle and that residual stresses appeared to play a minor role.

- It is evident that the discrete element approach similar to that used by Park, Kent and Sampson (23) for reinforced concrete could be used for steel sections if the stress-strain relationship is known. The section could be divided into a number of elements as in Fig. 34. The average strain in each element could be taken as that corresponding to the strain at the centre of the element. The internal forces on the section could be calculated from the strains, the stress-strain curve and the areas of the elements. For a given extreme fibre strain the neutral axis depth for equilibrium could be found by iteration and the corresponding moment and curvature calculated. The moment-curvature relationship could be obtained for any history of cyclic deformation. The discrete element technique would allow the complicated stress distributions arising from the non-linear cyclic stress-strain relationships to be handled more easily.

\subsection{Theoretical Determination of Load-Deflection Relationships for Structural Steel Members}

If the moment-curvature relationships of members are known then theoretically the rotations and deflections of members can be obtained from the moment-area equations (13) and (14). The curvature distribution along members at a particular stage of cyclic loading can be obtained from the history of previous moments and the cyclic moment-curvature relationships. Popov (41) and Krishnasamy and Sherbourne (4i) have demonstrated the effectiveness of this approach; experimentally obtained moment-curvature curves were used to calculate with very good accuracy the deflections of a cantilever under cyclic loading. Tanabashi, et al (13) have also calculated the deflections of simply supported wide-flange beams on the basis of theoretical curvature distribution found from an approximate approach using an equivalent sandwich section and obtained excellent agreement with test results.

Tests by Bertero and Popov (43), Tanabashi, et al (13) and others on wide-flange members under cyclic loading to large strains have found that local buckling of the flanges and torsional deformations have a considerable influence on the low-cycle fatigue life of the members. The life is less than that predicted from results from simple tension-compression specimens. The reason for this is that softening of the flanges of the members occurs due to the 
Bauschinger effect which reduces the tangent modulus of elasticity of the steel and causes the flanges to buckle after a few cycles. The moment carrying capacity of the member may not be much affected by such deformations. However during each cycle the buckles in the flanges tend to form and then partly straighten out as the flange is stressed in compression and then in tension. The result is a large fluctuation in strain. Bertero and Popov (43) found for example that fracture of steel cantilever beams occurred after only 16 cycles to a maximum strain of \pm 2.58 in the flange over the web. For a control strain amplitude of \pm 18 the number of cycles required to cause fracture was 650. Tanabashi, et al (13) have also compiled experimental data on the low-cycle fatigue life of wide-flange sections.

\subsection{Complete structures}

Tests reported by Massonnet and Save (29) have shown that theory for the failure of steel structures by progressive plastic deformation (incremental collapse) under repeated loading is conservative. However very little attempt has been made to follow through in detail the theoretical load-deflection response of structures. Goel and Berg (44) have used a Ramberg-Osgood moment-curvature expression (equation (20) and (21) ) for the girders of a multi-storey frame and to analyse the response of the frame to earthquake motions. This type of analysis gives a lead to a more accurate approach to the problem. Carpenter and Lu (45) in tests on full-size single bay steel frames subjected to constant vertical loading and reversed horizontal loading found stable loaddeflection hysteresis loops and maximum loads greater than expected from monotonic analysis. Strain hardening and residual $\mathrm{P}-\Delta$ moments were shown to play an important role. The problems of analysing complete structures of steel subjected to reversed loading may not be as great as for reinforced concrete but nevertheless there are difficulties concerning instability (local or overall buckling). Also the stiffness of connections (including degradation with repeated loading) and $P-\Delta$ effects need to be taken into account. Popov and Pinkney (46) have obtained some experimental evidence of the stiffness of connections. A great deal of analytical work remains to be conducted.

\section{CONCLUSIONS}

The following conclusions can be reached with regard to the present state of the theory for the strength and deformation of structures acted on by repeated and reversed loading.

\subsection{Materials}

The theory must of necessity be based on the stress-strain characteristics of the materials. Simplified stress-strain curves for repeated and reversed loading can be postulated but they are based on limited test data. In particular, comprehensive data is required for steel subjected to low-cycle fatigue loading at various strain rates. Evidence of the effect of high strain rates on the stress-strain curves under reversed loading is still very scarce.

\subsection{Reinforced Concrete}

Theoretical moment-curvature curves for reinforced concrete members subject to repeated and reversed loading can be derived assuming a linear strain profile and idealized stressstrain curves for the steel and concrete. Such theory shows good agreement with test results providing shear and anchorage deformations are negligible. The theory predicts the reduction in stiffness due to the Bauschinger effect of the steel and the open cracks in the compression zone which may eventually close. Generally the ultimate strength is unaffected by the reduced stiffness but is reached at greater deflections. For beams with equal top and bottem steel the moment-curvature loop is strongly influenced by the shape of the stressstrain curve for the steel and therefore closely resembles a Ramberg-osgood type loop. For beams with different steel areas top and bottom, and for columns, the moment-curvature loop shows a marked "pinched in" shape due to changes in stiffness caused by closing of cracks in the compression zone when the compression steel yields.

Theory for the load-defcrmation characteristics of framed structures is difficult to derive because under cyclic loading (for example, from earthquake motions) deformations in addition to those caused by flexure occur due to shear (particularly at plastic hinge sections). deterioration of anchorage of bars (particularly at beam-column joints) and deformation in beamcolumn joints. More evidence is required of these additional deformations before accurate load-deformation characteristics of reinforced concrete frames can be determined. Very little work has been conducted to determine the behaviour of complete structures under repeated and reversed loading.

\subsection{Prestressed Concrete}

Theoretical moment-curvature relationships for repeated and reversed loading can be accurately obtained. These indicate that before crushing of concrete commences prestressed concrete members show a high recovery of deformations and because of the narrow hysteresis loops little energy is dissipated. At larger deformations after crushing the recovery is still great but the energy dissipation is much larger.

\subsection{Structural steel}

Most investigators have used Rambergosgood type functions to represent the stressstrain and moment-curvature hysteresis loops of wide flange steel members under reversed loading, but there has been surprisingly little theoretical work conducted in this area. This has been mainly due to the lack of comprehensive stressstrain data. A great deal of analytical work remains to be conducted.

\section{REFERENCES}

1. Popovics, S., "A review of Stress-Strain Relationships for Concrete", Journal of the American Concrete Institute, Proceedings Vol. 67, No. 3, March 1970, pp. 243 - 248.

2. Kent, D.C. and Park, R., "Flexural Members with Confined Concrete", Proceedings of the American Society of Civil Engineers, ST7, July, 1971, pp. 1969 - 1990.

3. Hatano, T. and Tsutsumi, H., "Dynamical Compressive Deformation and Failure of Concrete Under Earthquake Load" , Proceedings of 2nd World Conference on Earthquake Engineering, Vol. III, Japan, 1960, pp. 1963-1978. 
4. Bar, S. and Mugumuna, H. "geharzoux of

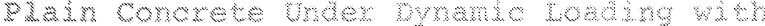
Strakning rate Comparable to Ratchovake

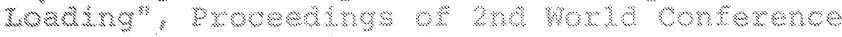

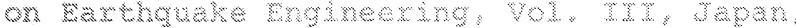
1960, pp. 1979 -.. 1993.

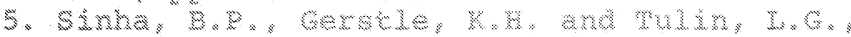

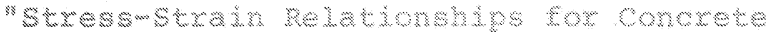
Under cyolie woadng", wournal of the

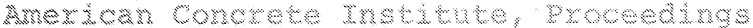
vol. 61; No. 2, Rebruary 1964, pp. 195 - 211.

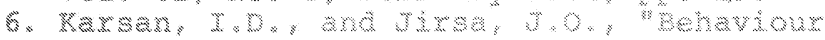
of Concrete Under Compressive Loadings" Procesdnge of the Ruterken sochety of civin

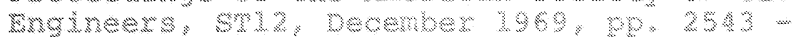
2563.

7. Shah, s, and Wuter, G., Response or concrete to Repeated Woadung" Procecdings of Trtermathonal symposum on the cerects of Repeated Hoadng of Materhals and

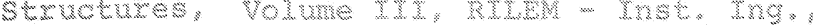
Mexsco, 1966.

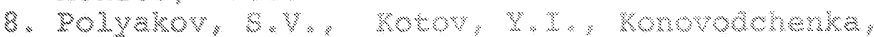

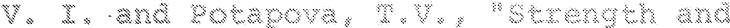
Defommatsons of Concrete, Masonry and Mountes Undex Raphd oncempplied and Repeated Road

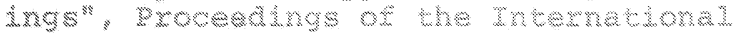

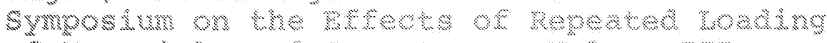
of Material a and structrres. Volvme $\mathrm{Tu}$. RTWEM - Mnst. Mng. Mexice, 1966

9. Rolyakov, B. V., Becheneva, K. V., Kotov, Ju. . .

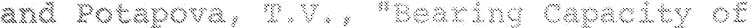

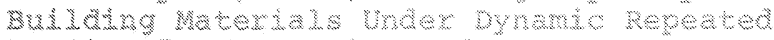

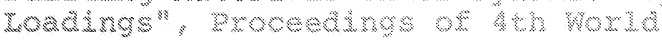

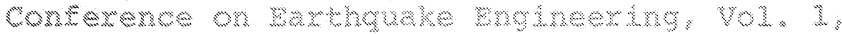
chile, $2969, \mathrm{pp}, \mathrm{B}-\mathrm{-}, 2,195-208$.

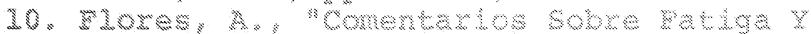

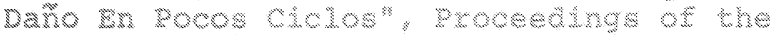

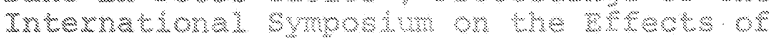

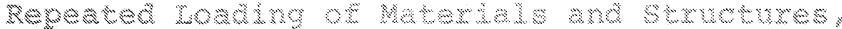

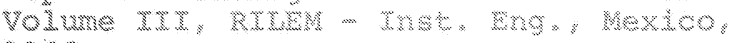
1966.

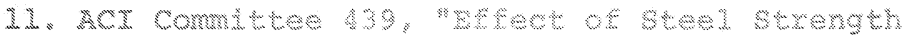
ard of Reduforcenent hat 20 on the Mode of

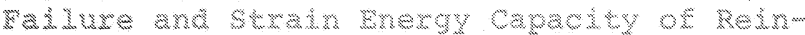

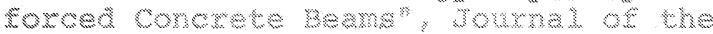

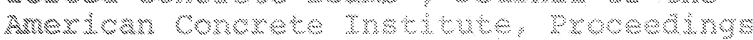
Vol. 66, No* 3 , March 1969, pq. $165-173$

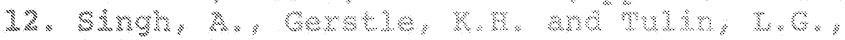

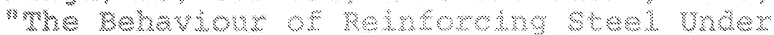
Reversed Moding" Materials Recexch and sturdaxds, Nol. 5, No. 1, Tanuary 1965. pp. $12 \cdots 17$.

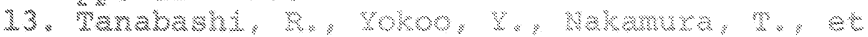

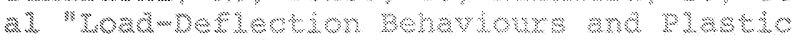

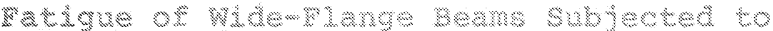

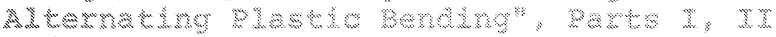

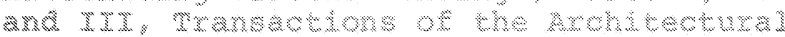
Institute of rapar, September, octobet and November. 1970

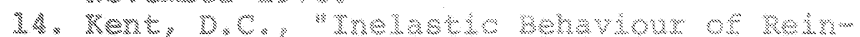

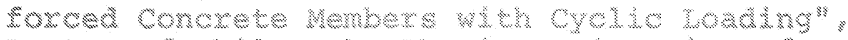

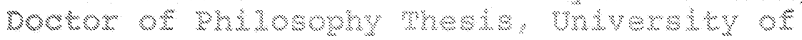
camberbury, New zealand, 1969, po. 246 plus appendices.

15. Kert D.C., and Park, R. "Cyclic woad

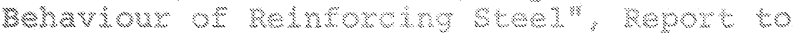
be published.

16. Rambers, W. and pegood, W.R. " Deseription of the Stress-berain curves by muxes

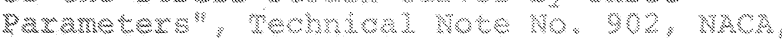
Tw24 1943.

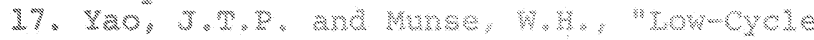

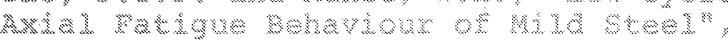

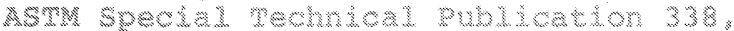
pp. $5-24.24$.

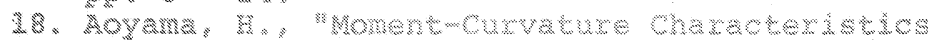
of Rexroreed Concrete Members subjected to Rxsal hoad and heversal of bending", proceedinge of the rokernetional. sympostum on the ruexural Mechentos of Retnforces concrete, ASCE-ACY, Rloride, $1964, \mathrm{pP}$ $183-212$

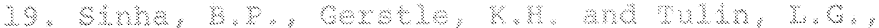
"Responee of eungly kesnforced Beams to Cyclio Loadng" Moumal of the American

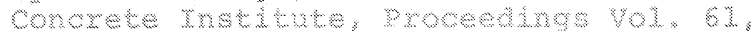
No. 8, Rugres $2964, \mathrm{pp}, 1021$ - 1038.

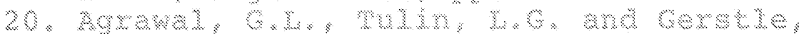
R.R. "Respones of Doubly ke knkoreed

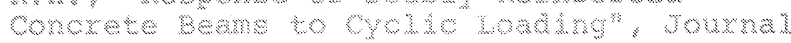

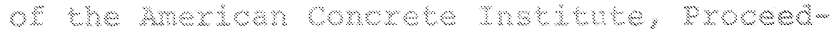
Inga vol. 62, No, 7, July 1965, pe. 823 … 836.

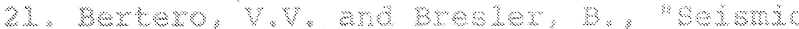
Beheysour of keinforced. Concrete kramed structures" proceedrnge of the 4th World

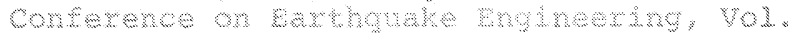

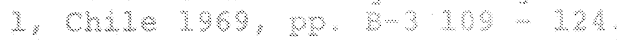

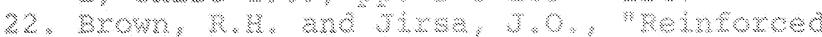
concrete beams under revereed zodhns"

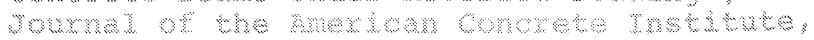
moceedrase Vol. 68, No, s, May $1972, \mathrm{pp}$. $380-390$

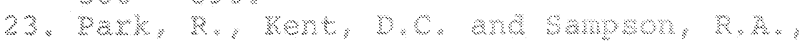
"ReAnforced Concrete Membere wh cyckio Modurng", Proceedings of the Anertoen

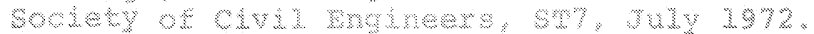

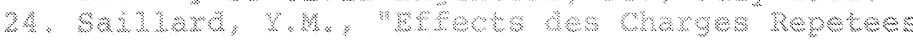
swx 1es structures" proceed ange of the whermetronal symposum on the pistects of Repeated rooding of Maberials and struetures,

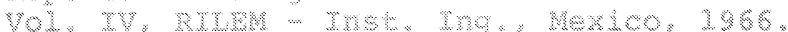

25. Manson N.W. and Comon, B. W. "sesmis Res 1sthee of Relnkorced Conorete Beamo

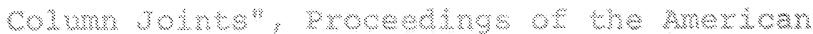
sockery of clvil Enchneere, $701.93,545$ october 1967, pe. 533 w 560.

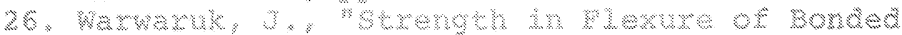
and unbonged prestresed conctete beams"

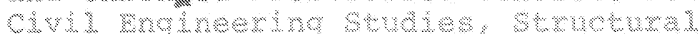

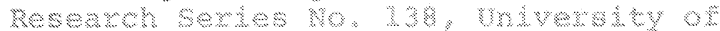
Murnoks, Avenst 1967.

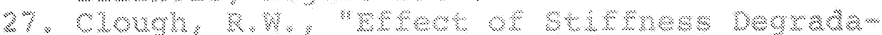
tron on Barthoudke Dnet11'by Requlxemente.

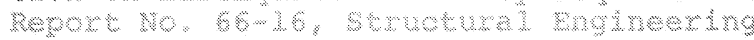

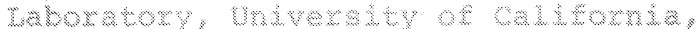
october $3966,9.67$

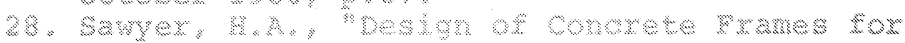

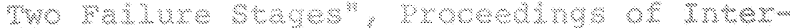

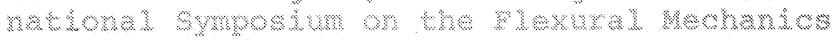

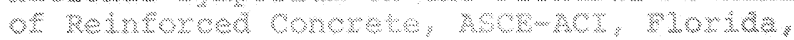
1964, pe. 405 … 43 ?

29. Masponnet, C.8. and save, M.X., M 1 astho And Lyele and Desion, pol: 2 , Beans and

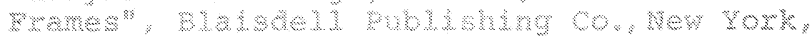
2965, pp. $229-242$.

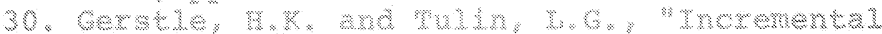
Decormattons of Under melnfored conorete Bedme" Ragazkne of Concrete Regeaxch; Vol. 23. No, 77, December 1971, pe, 161 - 168 .

31. Megoet, R.M. and Raxk, R. "Relnkored

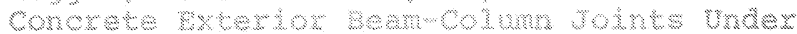

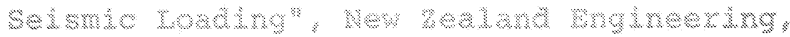
Vol. 26, No. 11 , November 1971, pp. 341 .' 353.

32. Umemura, 4 , and Moyama, $\mathrm{k}$, "Gvaluation of

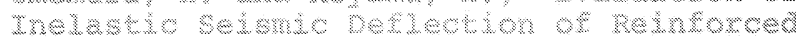
comcrete mrames sased on the rester of

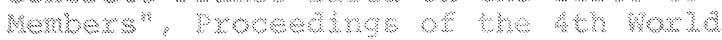

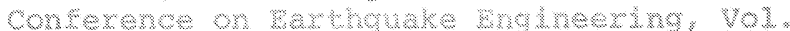
1. chile 1969, pp. 8-2 $91-108$.

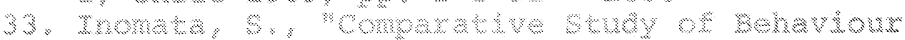
of prestressed and Rednforced Comorete Beams Subyected to Reversed Roading p rournal of rapar prestrebsed concrete Brolnearno Kasockation, Vo1, 11, Mo. 2, Marek 1969.

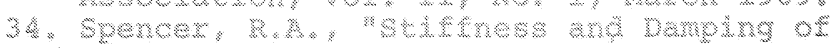


Nine Cyclically Loaded Prestressed Concrete Members", Journal of the Prestressed Concrete Institute, Vol. 14, No. 3, June 1969, pp. $39-52$.

35. Paranagama, D.D.O. and Edwards, A.D. "Moment-Deformation Characteristics of Pretensioned Concrete Beams Subject to Fluctuating Loads", Journal of Prestressed Concrete Institute, Vol. 14, No. 4, August 1969, pp. 62 - 74 .

36. Blakeley, R.W.G., "Ductility of Prestressed Concrete Frames Under Seismic Loading", Doctor of Philosophy Thesis, University of Canterbury, New Zealand, 1971, pp. 230. plus appendices.

37. Blakeley, R.W.G. and Park, R., "Prestressed Concrete Sections Under Cyclic Flexure", Report to be published.

38. Blakeley, R.W.G. and Park, R., "Seismic Resistances of Prestressed Concrete BeamColumn Assemblies", Journal of the American Concrete Institute, Proceedings Vol. 68, No. 9, September 1971; pp. 677 692.

39. Kaldjian, M.J., "Moment-Curvature of Beams as Ramberg-Osgood Functions" "Proceedings of the Annerican Society of Civil Engineers, Vo1. 93, ST5, October 1967, pp. $53-65$.

40. Jennings, P.C. " Response of Simple Yielding structures to Earthquake Excitation", Doctor of Philosophy Thesis, California Institute of Technology, Pasadena, 1963.
41. Popor, E.P., "Low Cycle Fatigue of steel Beam to Column Connections", Proceedings of the International symposium on the Effects of Repeated Loading of Materials and Structures, Vol. VI, RILEM - Inst. Ing. . Mexico, 1966.

42. Krishnasamy, S. and Sherbourne, A.N. "Mild Steel Structures Under Reversed Bending", Proceedings of the International symposium on the Effects of Repeated Loading of Materials and Structures, Vol. IV, RILEM - Inst. Ing., Mexico 1966.

43. Bertero, V.V. and Popov, E.P., "Effect of Large Alternating Strains of Steel Beams" Proceedings of American Society of Civil Engineers, Vol. 91, STl, February 1965, pp. 1 - 12 .

44. Goel, S.C. and Berg, G.V." "Inelastic Earthquake Response of Tall steel Frames", Proceedings of American Society of Civil Engineers, Vol. 94, ST8, August 1968, pp. 1907 - 1934.

45. Carpenter, L.D. and Lu, L-W., "Repeated and Reversed Load Tests on Full-Scale Steel Frames", Proceedings of the 4 th world Conference on Earthquake Engineering, Vol. I, Chile, 1969, pp. B-2 125 - 136.

46. Popov, E.P. and Pinkney, R.B., "Reliability of Steel Beam-to-Column Connections Under Cyclic Loading", Proceedings of the $4 \mathrm{th}$ World Conference on Earthquake Engineering, Vol. II, Chile, 1969, pp. B-3 I5 - 30 .

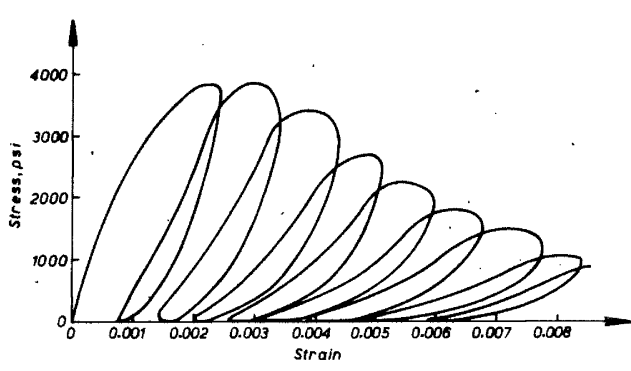

Fig. 2 Stress-Strain Curve for Concrete With Repeated Compressive Loading (5).

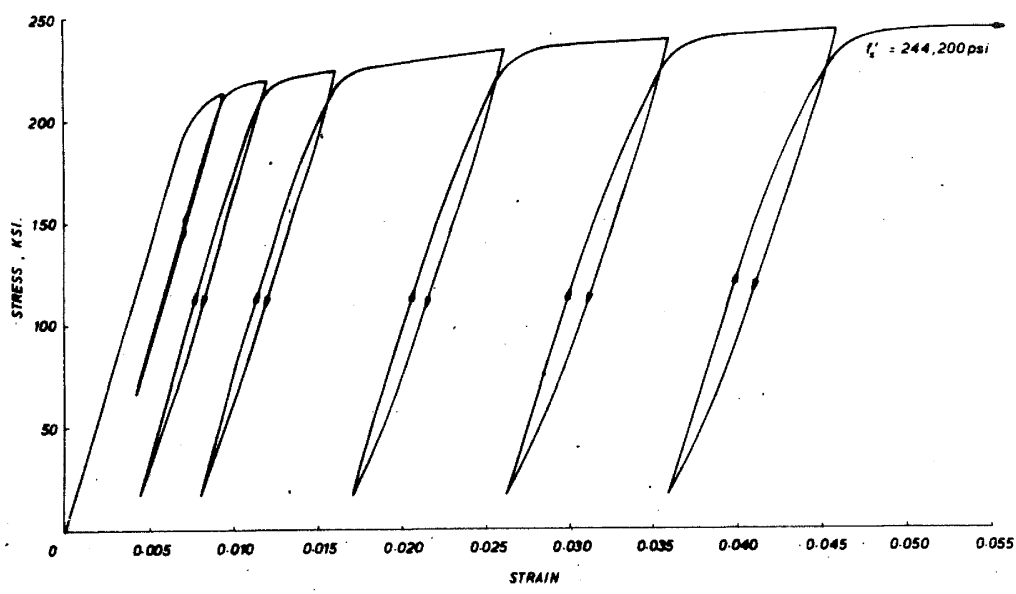

Fig. 4 Stress-Strain Curve for $7 \mathrm{~mm}$ Diameter High Tensile Steel Wire with Repeated Tensile Loading (36).
Fig. 3 Stress-Strain Curve for Steel With Repeated Loading.

Fig. 1 Effect of Time to Failure on Stress-Strain Curve for Concrete in Compression (3).

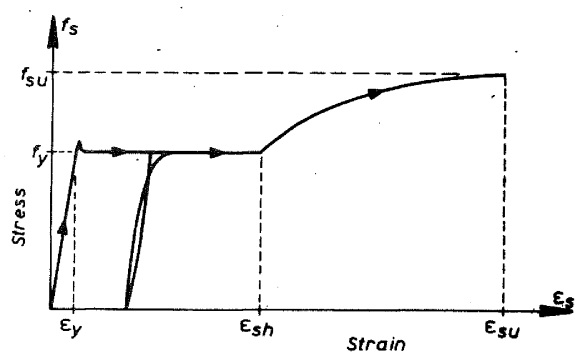




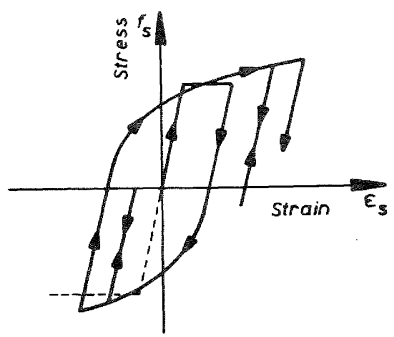

Fig. 5 Stress-Strain Curve for Steel With Reversed Loading.

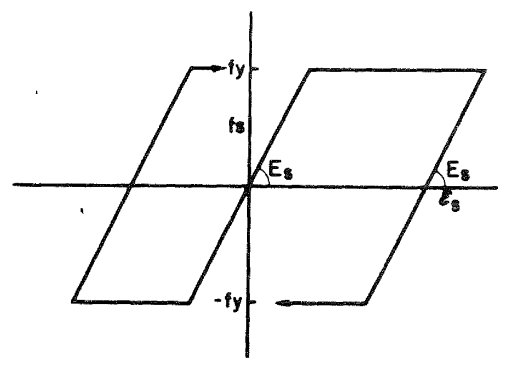

(a) Stress Strain Relationship of Steel

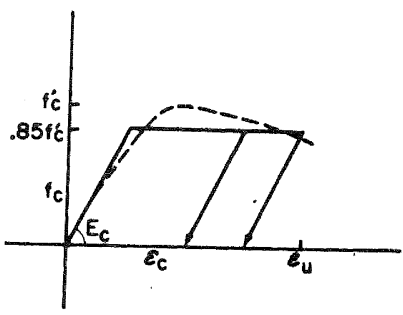

(b) Stress Strain Relationship of Concrete

Fig. 6 Stress-Strain Relationships Assumed by Aoyama (18).
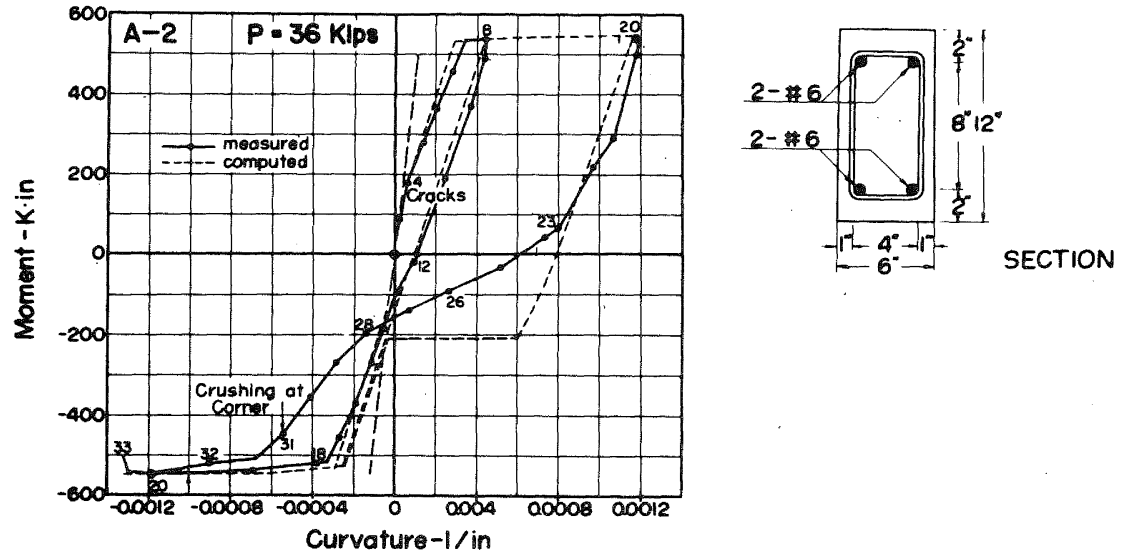

Fig. 7 Moment-Curvature Diagrams for Aoyama's Beam A-2 (18).

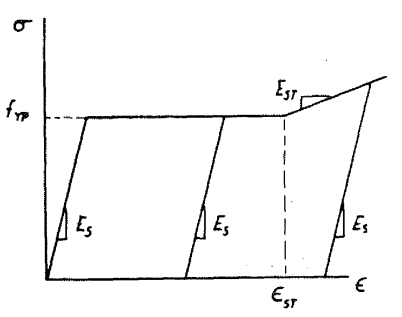

(a) Steel

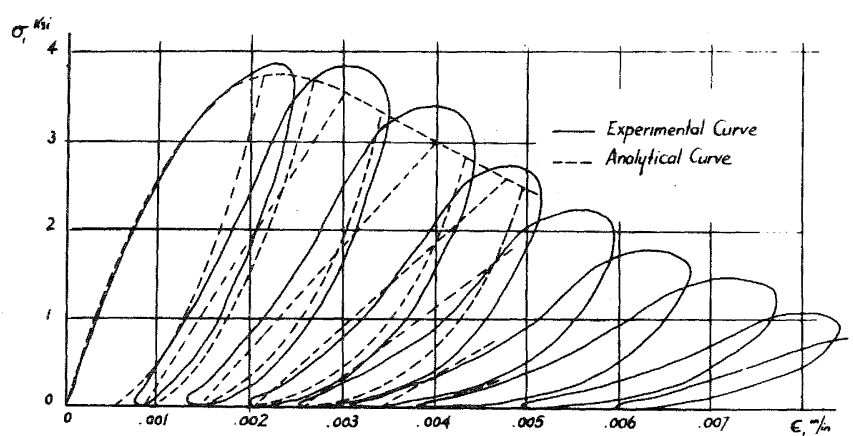

(b) Concrete

Fig. 8 Stress-Strain Relationships Assumed by Sinha, et al (19). 


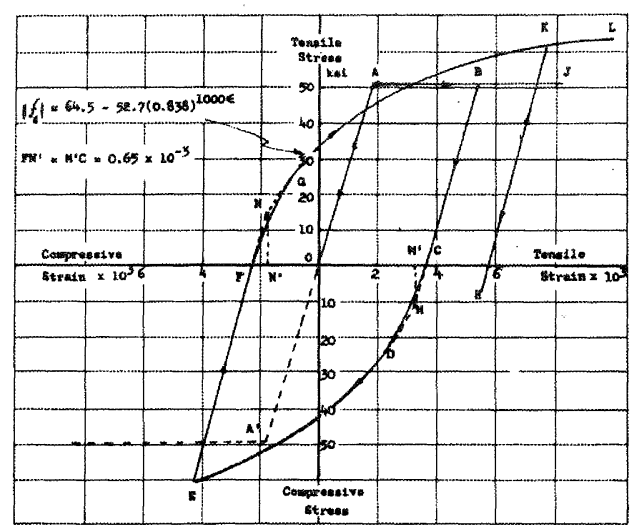

(a) Steel

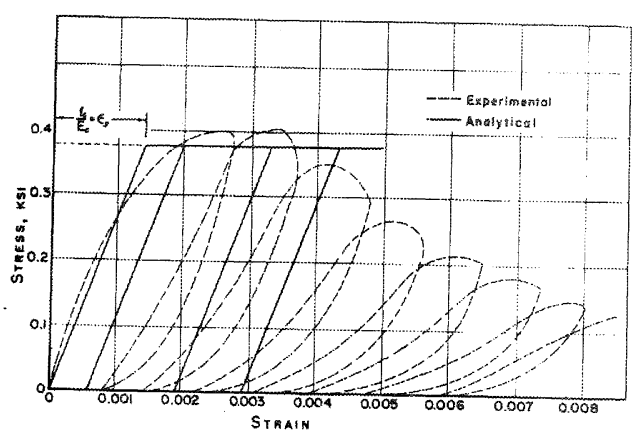

(b) Concrete

Fig. 9 Stress-Strain Relationships Assumed by Agrawal, et al (20).

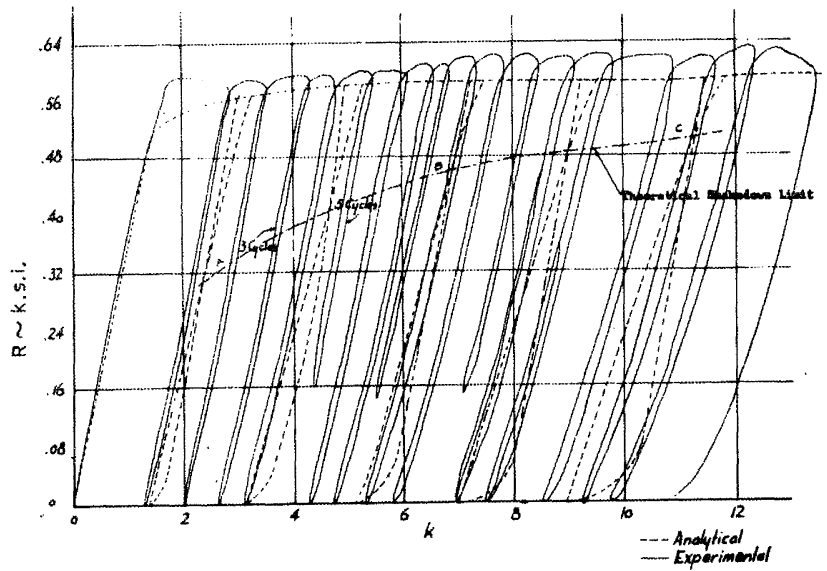

Fig. 10 Moment-Curvature Curves for a. Singly Reinforced Beam $(\mathrm{p}=1.4 \%)$ (19).

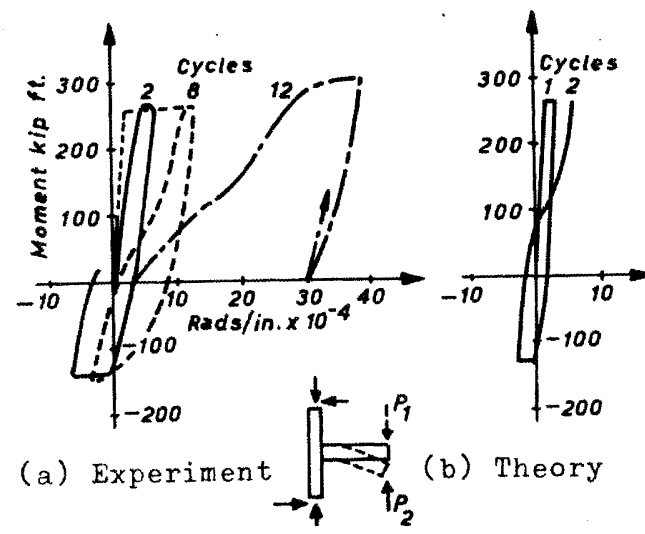

Fig. 12 Moment-Curvature Curves for Beam Section $(21,25)$.

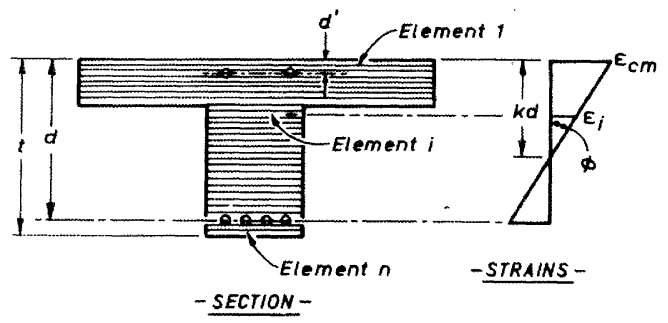

Fig. 14 Discrete Elements for a T-Section (23).

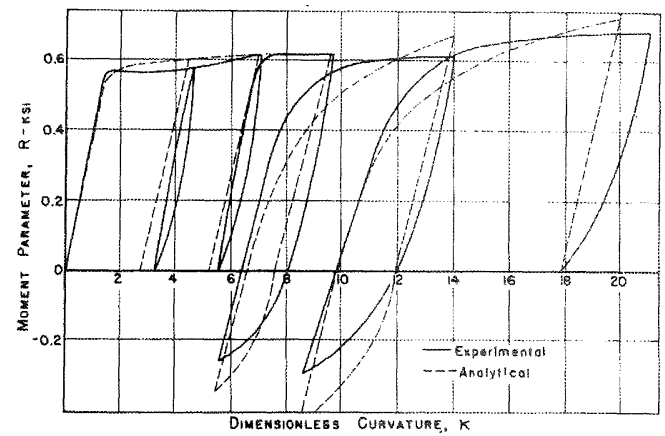

Fig. 11 Moment-Curvature Curves for a Doubly Reinforced Beam $\left(\mathrm{p}=\mathrm{p}^{\prime}\right)(20)$.

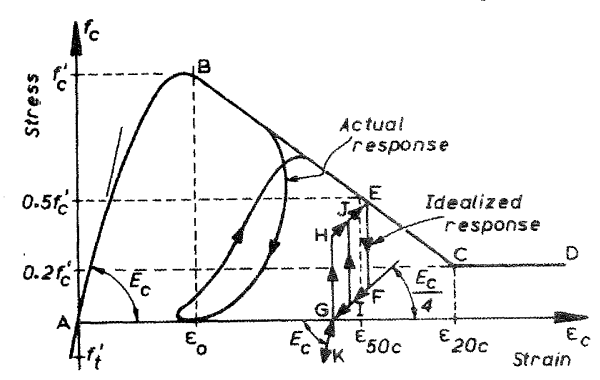

Fig. 13 Stress-Strain Relationship Assumed for Concrete (23).

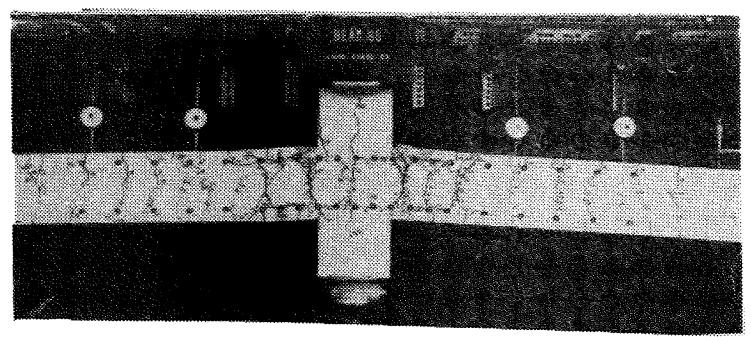

Fig. 15 Beam 65 with $p=1.77 \%$, $\mathrm{p}^{\prime}=1.12 \%$ and $\mathrm{p}^{\prime \prime}=0.77 \%$ After Cyclic Load Testing (23). 


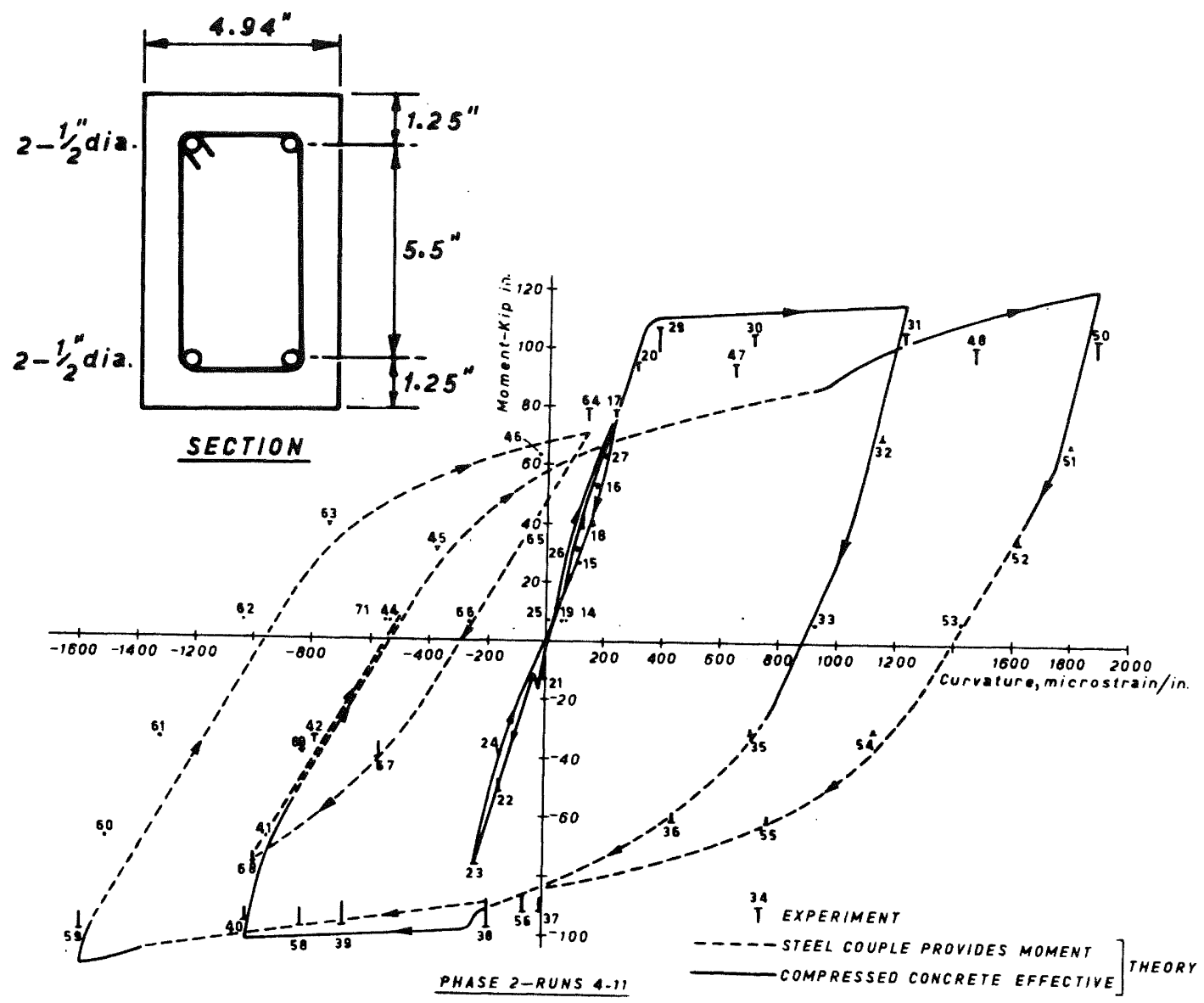

Fig: 16 Moment-Curvature Curves for Critical Section of Beam 24 with $\mathrm{p}=1.11 \%, \mathrm{p}^{\prime}=1.11 \%$ and $\mathrm{p}^{\prime \prime}=2.30 \%(23)$.
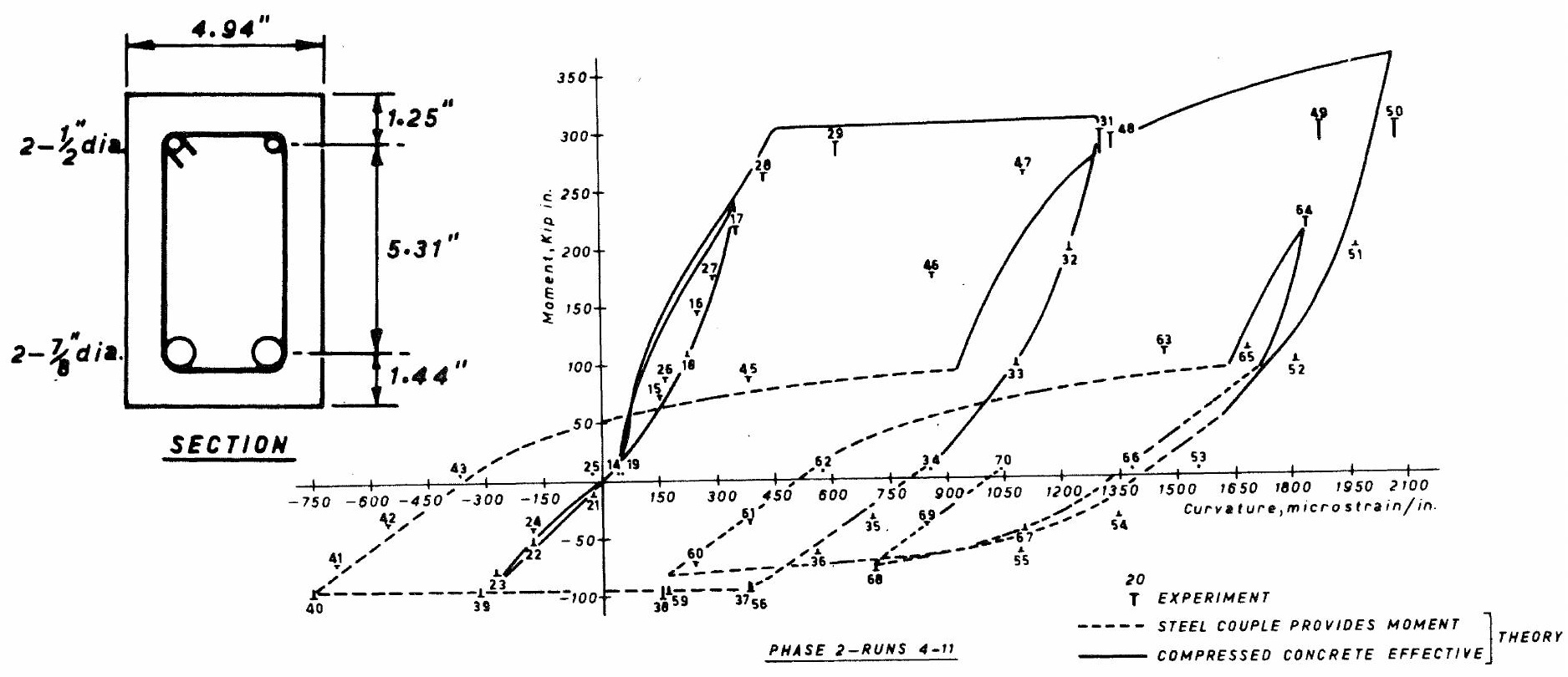

Fig. 17 Moment-Curvature Curves for Critical Section of Beam 27 with $\mathrm{p}=3.54 \%, \mathrm{p}^{\prime}=1.14 \%$ and $\mathrm{p}^{\prime \prime}=2.30 \%$ (23). 


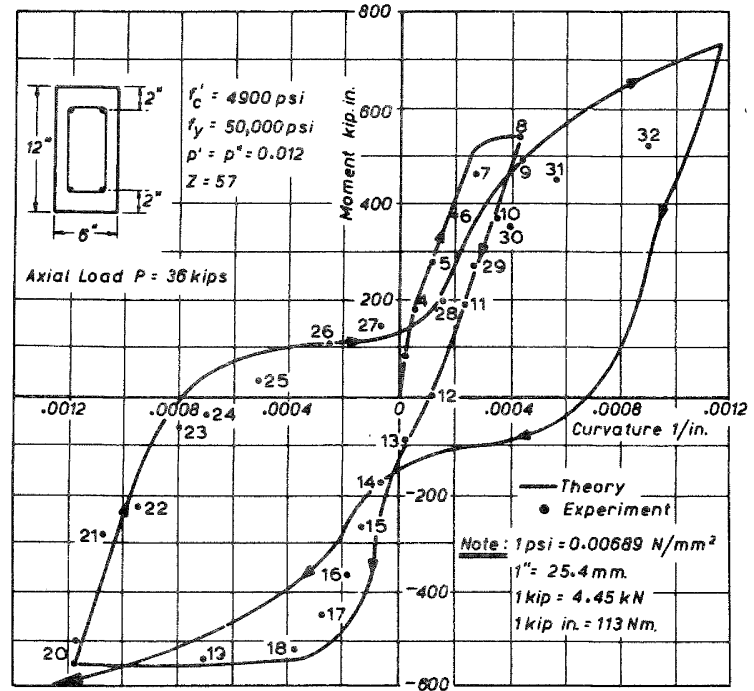

Fig. 18 Moment-Curvature Curves of Aoyama's Specimen A-2 With Axial Load and Flexure.

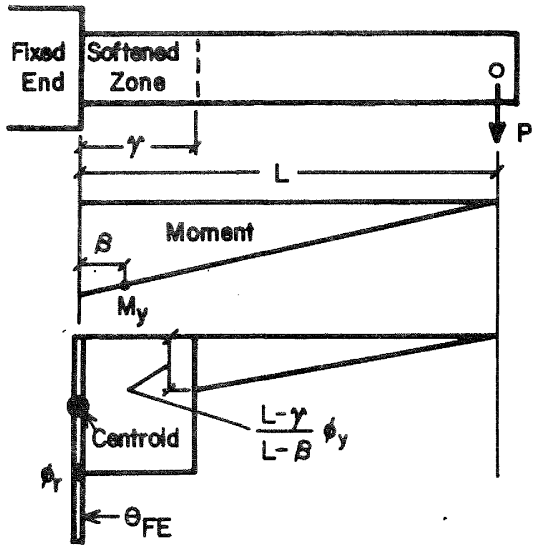

Fig. 20 Moment and Curvature Distribution Assumed by Brown and Jirsa (22).

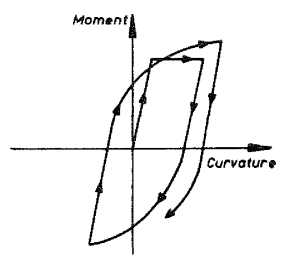

(a) Ramberg-Osgood response

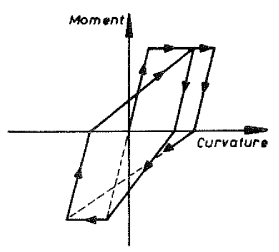

(b) Clough's degrading stiffness response

Fig. 19 Idealized MomentCurvature Responses.

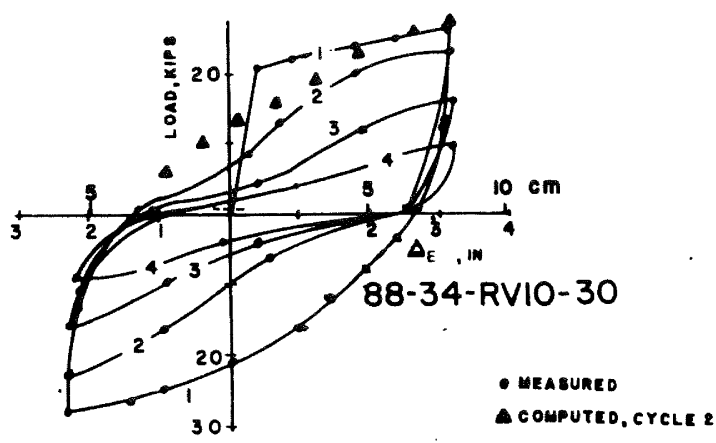

Fig. 21 Load-End Deflection Curves for Cantilever $\left(\mathrm{p}=\mathrm{p}^{\prime}=2.6 \%\right)$ (22).

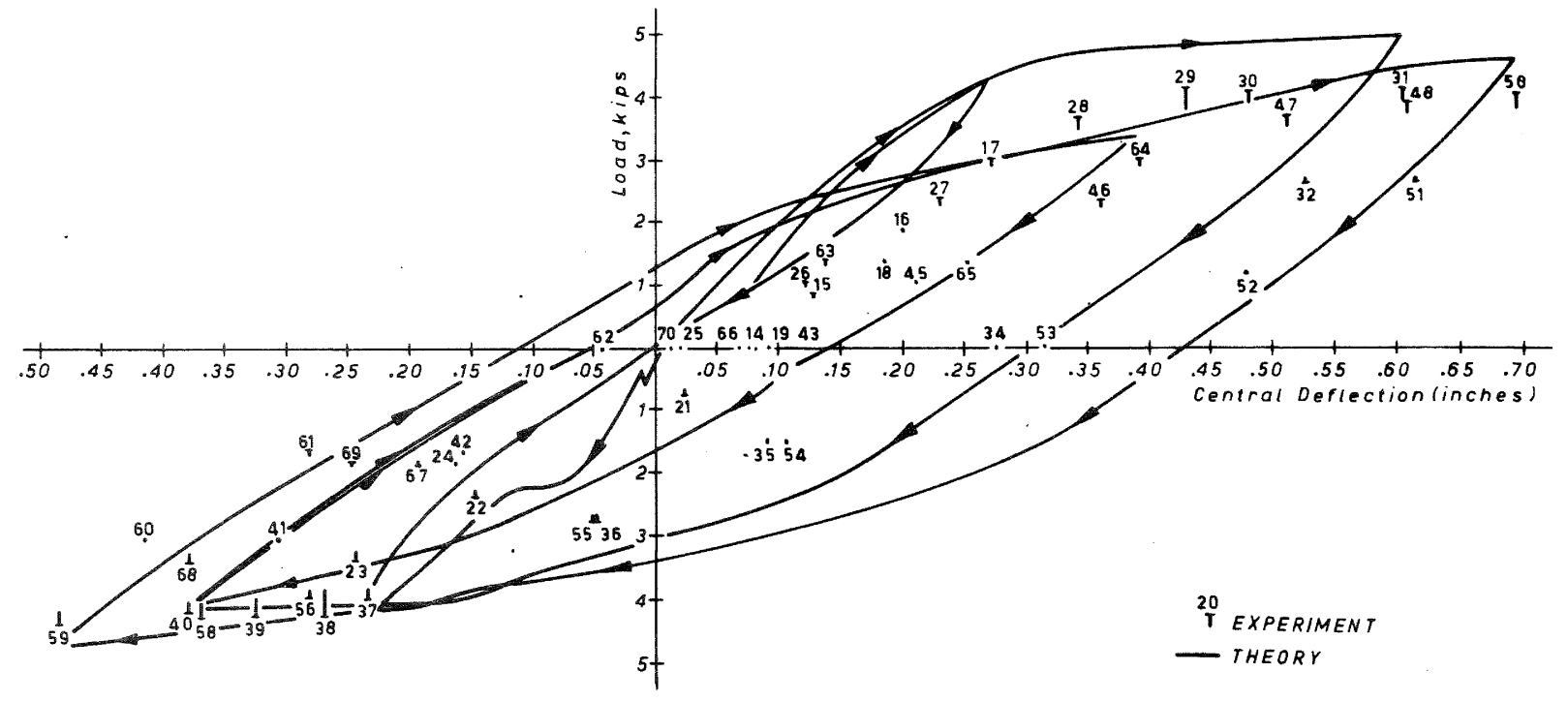

PHASE 2-RUNS 4-11

Fig. 22 Load-Central Deflection Curves for Beam 24 with $p=p^{\prime}=1.11 \%$ (23). 


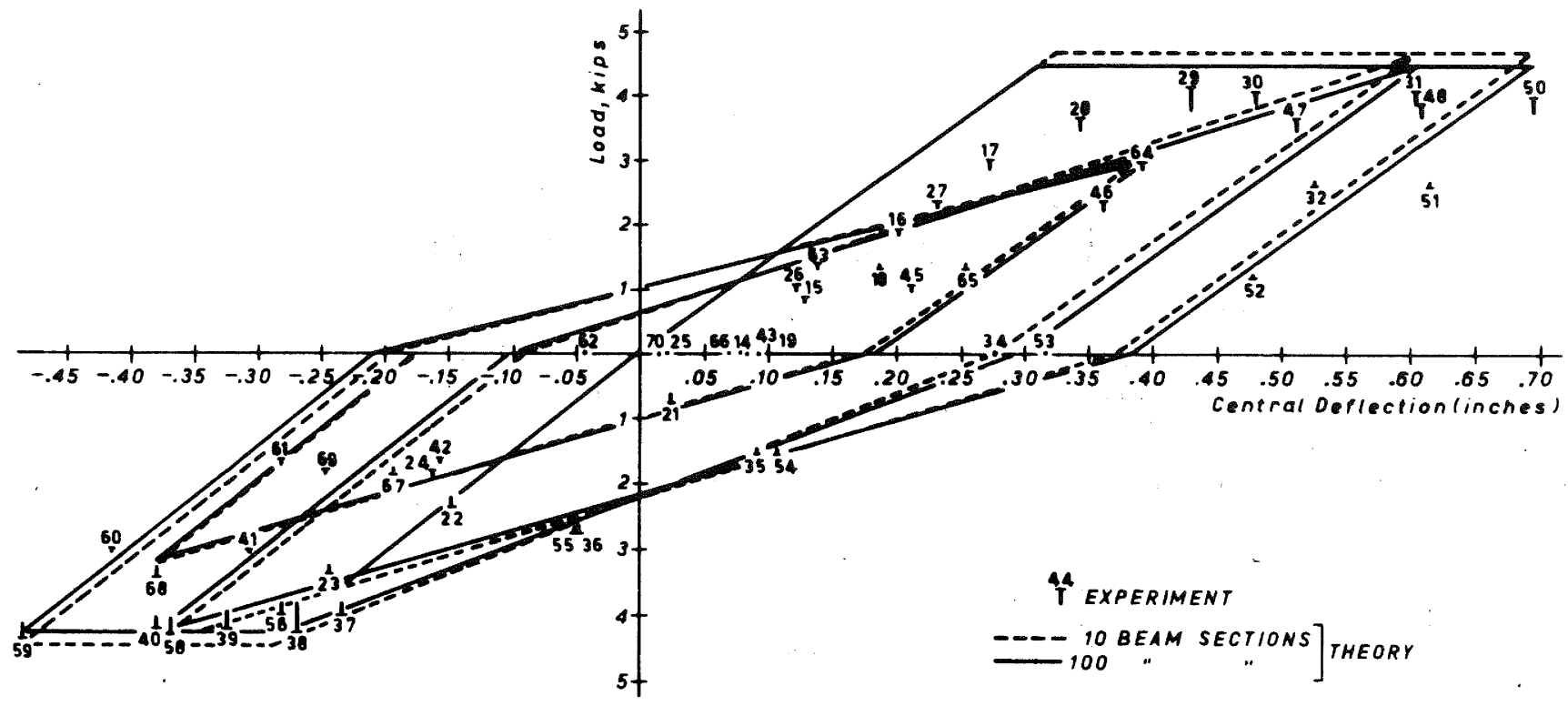

PHASE 2-RUNS 4-11

Fig. 23 Load-Central Deflection Curves for Beam 24 Using Clough's Response (23).

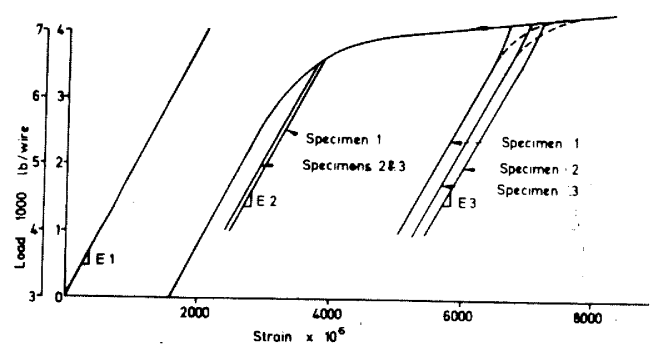

(a)

Steel

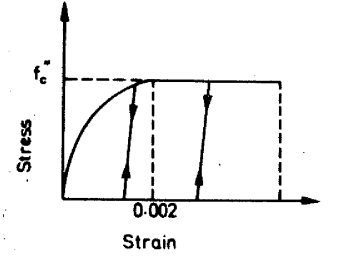

(b)

Concrete

Fig. 24 Stress-Strain Curves Assumed by Paranagama and Edwards (35).

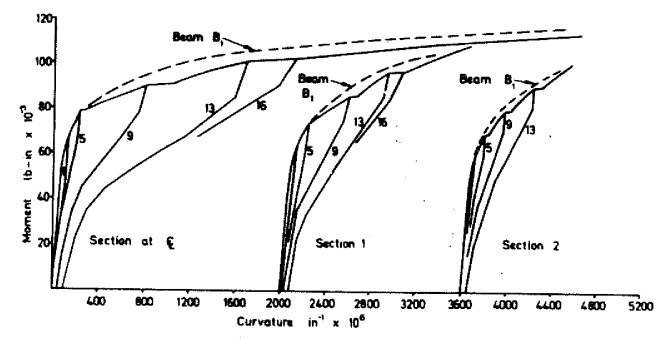

Fig. 25 Experimental MomentCurvature Curves for a Beam (35).

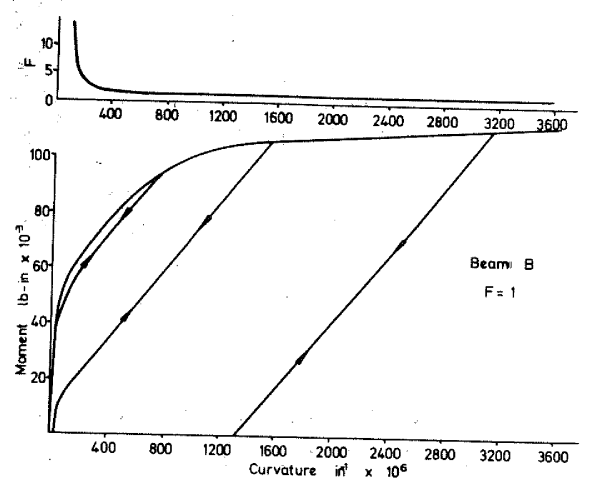

Fig. 26 Theoretical MomentCurvature Curves for a Beam and Required F (35). 


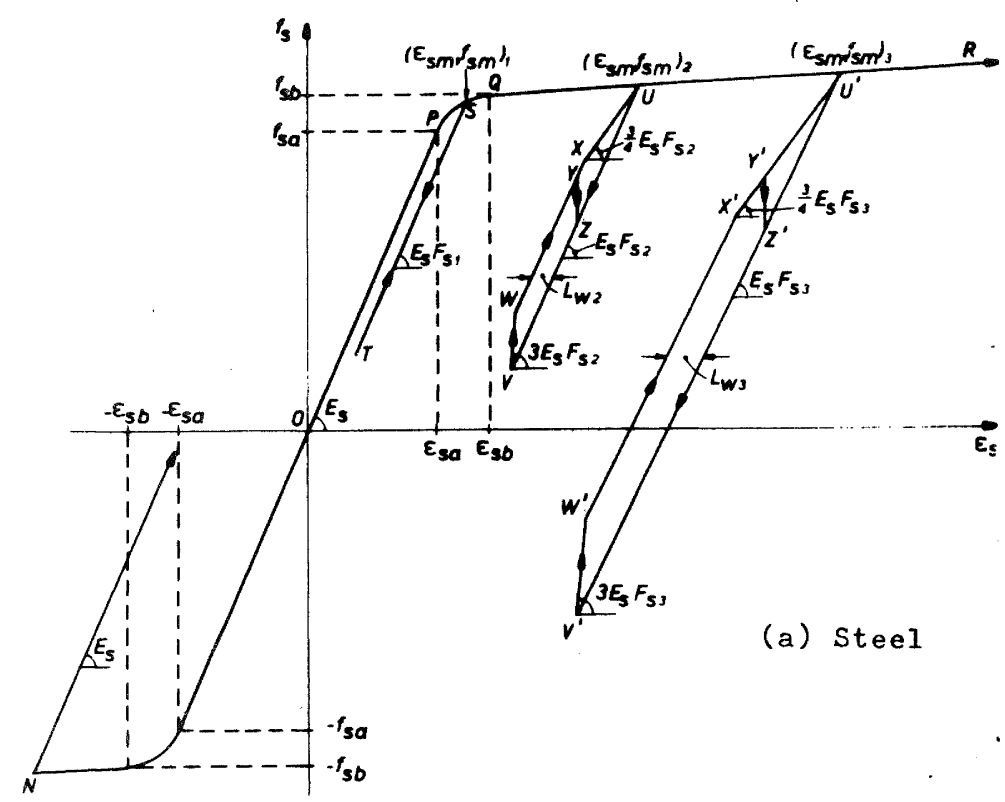

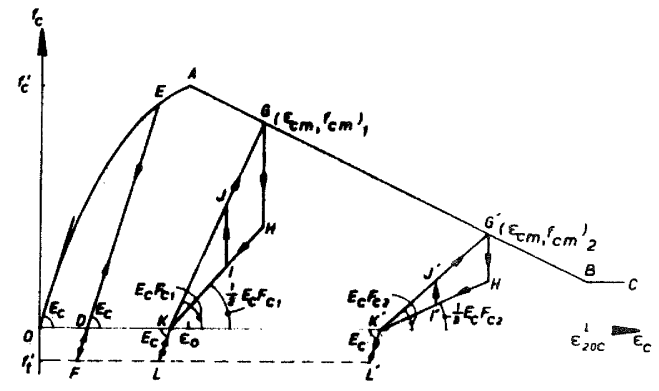

(b) Concrete

Fig. 27 Stress-Strain Relationships Assumed by Blakeley and Park $(36,37)$.
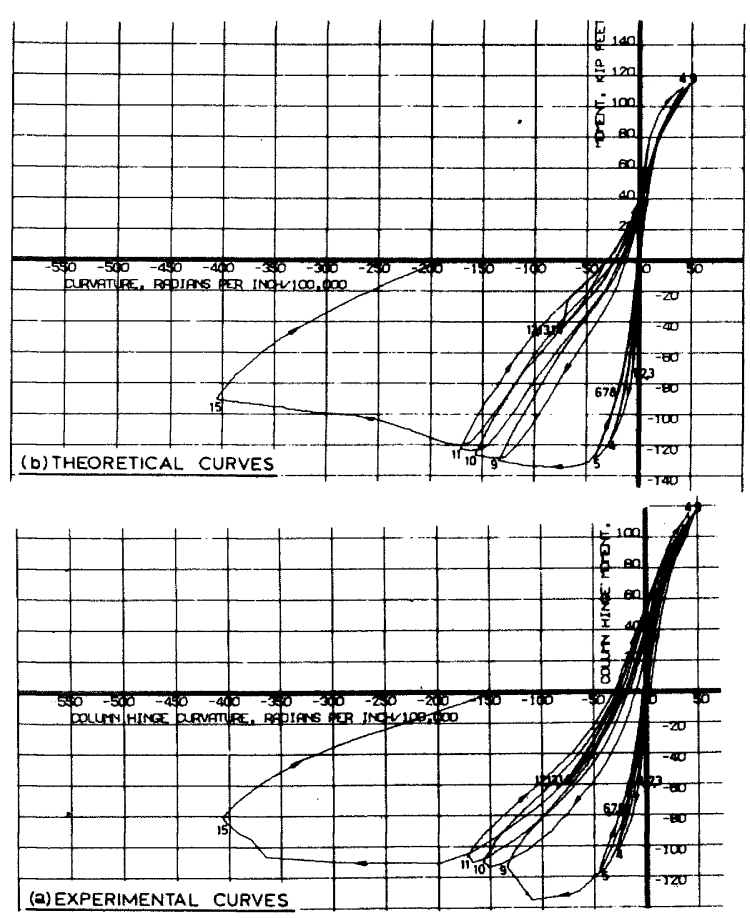

Fig. 28 Moment-Curvature Curves for Unit 3 Column $(36,37)$.

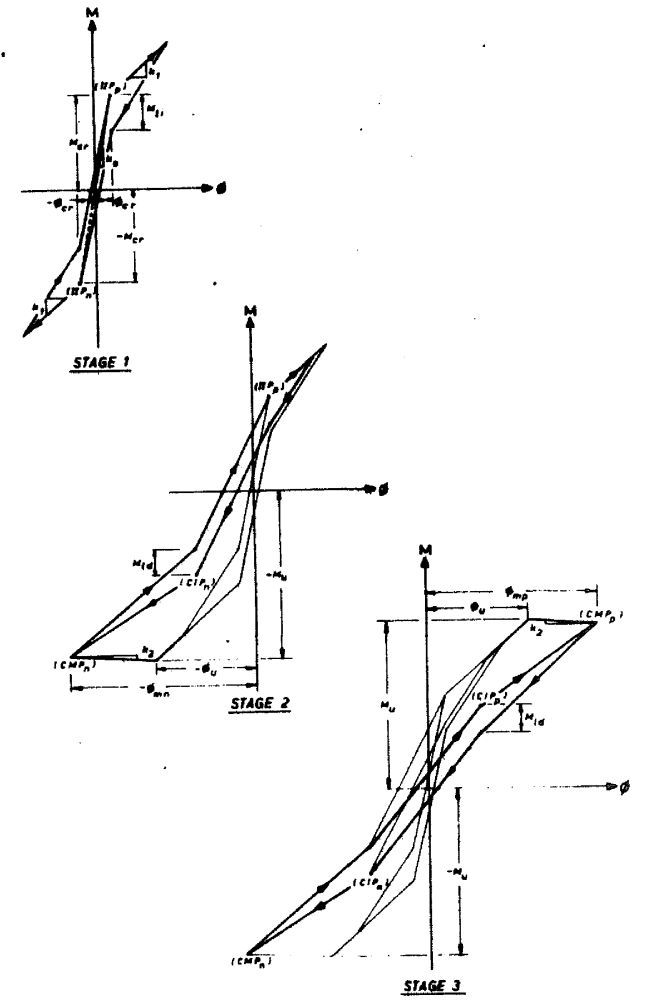

Fig. 29 Moment-Curvature Idealizations $(36,37)$. 


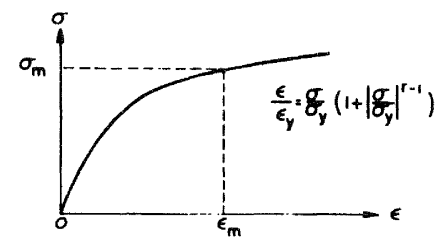

Fig. 30 Stress-Strain Curve for Steel Assumed by Kaldjian (39).
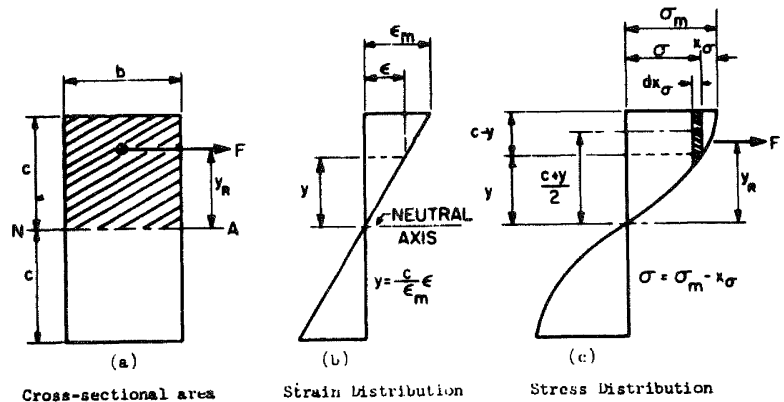

Stress Listribution

Fig. 31 Strain and Stress

Distribution (39).

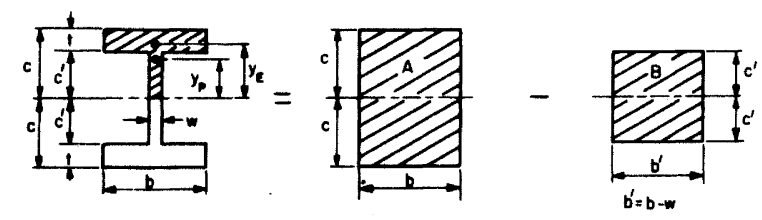

Fig 32 Wide-Flange Section Approximation (39).

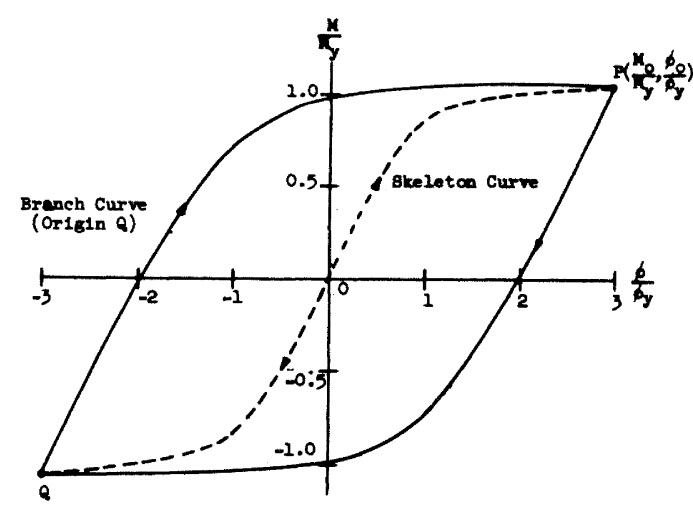

Fig. 33 Ramberg-0sgood Skeleton and Branch Curves.

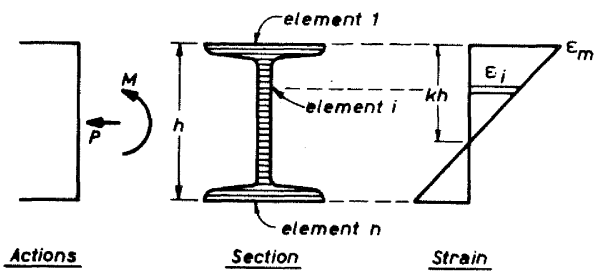

Fig. 34 Discrete Element Approach for Steel Sections. 